\title{
ENVIRONMENTAL SURVEILLANCE FOR FUEL FABRICATION PLANTS
}

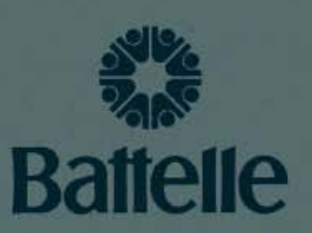

Pacific Northwest Laboratories Richland, Washington 99352

\section{APRIL 1973}

Prepared for the U.S. Atomic Energy Commission under Contract AT(45-1):1830 


\section{NOTICE}

This report was prepared as an account of work sponsored by the United States Government. Neither the United States nor the United States Atomic Energy Commission, nor any of their employees, makes any warranty, express or implied, or assumes any legal liability or responsibility for the accuracy, completeness or usefulness of any information, apparatus, product, or process disclosed, or represents that its use would not infringe privately-owned rights.

PACIFIC NORTHWEST LABORATORY

operated by

BATTELLE

for the

U.S. ATOMIC ENERGY COMMISSION

Under Contract AT(45-1)-1830

Printed in the United States of America

Available from

National Technical Information Service

U.S. Department of Commerce.

5285 Port Royal Road

Springfield, Virginia 22151

Price: Printed Copy \$3.00; Microfiche $\$ 0.95$

ATC:DL nICMLAND. wasG 
BNWL-1723

\section{9}

\section{ENVIRONMENTAL SURVEILLANCE FOR}

FUEL FABRICATION PLANTS

by

J. P. Corley and D. A. Waite

Occupational and Environmental Safety Department Environmental Evaluations Section

J. W. Johnston

Mathematics and Physics Research Department Statistical Design and Analysis Section

and

L. C. Schwendiman

Atmospheric Sciences Department Atmospheric Analysis Section

Apri1 1973

BATTELLE

PACIFIC NORTHWEST LABORATORIES

RICHLAND, WASHINGTON 99352 


\section{FOREWORD}

The Atomic Energy Commission, through Fuels and Materials, Directorate of Licensing, established a contract with the Battelle-Northwest Laboratory to conduct a study on "Environmental Surveillance for Fuel Fabrication Plants." The results of this study are contained in this report. 


\section{TABLE OF CONTENTS}

Page

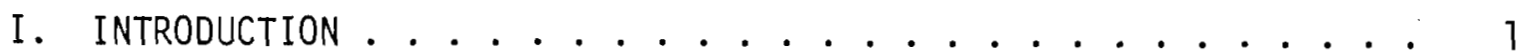

1. Purpose and Scope. . . . . . . . . . . . . 1

2. Environmental Surveillance Rationale ........ 2

3. Terminology. ................. 3

II. STANDARDS AND CRITERIA ..................... 4

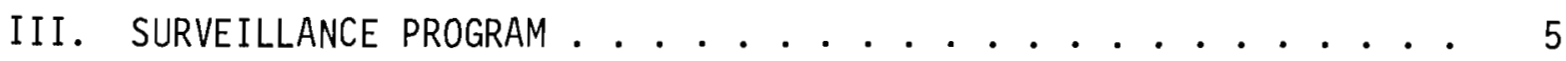

1. Program Basis. . . . . . . . . . . . 5

2. Critical Pathway Analysis and Calculation. ...... 5

3. Statistical Applications ............... 9

a. Estimates of Concentration .......... 9

b. Tests of Hypotheses and Trends .......... 11

4. Program Description. . . . . . . . . . 11

a. Air Surveillance . . . . . . . . . . 11

(1) Equipment ................... 11

(2) Radionuclides ............... 13

(3) Fluorine Compounds. . . . . . . . . . . 14

(4) Compounds of Nitrogen ............ 16

(5) Sample Locations. ............. 18

(6) Sample Collection and Analysis......... 20

(7) Quality Controls.............. 21

b. Water Surveillance ............. 21

(1) Surface Water.............. 21

(2) Groundwater................. 24

(3) Sample Analysis . . . . . . . . . . . 24

c. Surveillance of Other Media. . . . . . . . 25

(1) Foodstuffs. . . . . . . . . . . . 25

(2) Soi1, Sediment, and Vegetation........ 26

(3) Deposition Collectors ............ 28 
TABLE OF CONTENTS (Continued)

Page

5. Preoperational Program ............... . . 29

a. Objectives ................. . . 29

b. Checklist................ 31

-Air...................... 31

-Water....................... 31

-Other Media . . . . . . . . . . . . 32

-Al1 Media................. 32

6. Data Records and Reports.............. 33

a. Records. . . . . . . . . . . . 33

b. Data Evaluation. ............. 33

c. Reports................ 35

BIBLIOGRAPHY ......................... 37

APPENDIX A - Applicable Federal Regulations on Environmental Radioactivity. ................... A-1

APPENDIX B - Applicable Federal Regulations on Nonradioactive Environmental Contaminants. . . . . . . . . B-1

APPENDIX C - Minimum Analytical Detection Limits . . . . . . . . C C-1

APPENDIX D - Some Statistical Considerations and an Index of Adequacy for an Environmental Surveillance System. . . . . . D-1

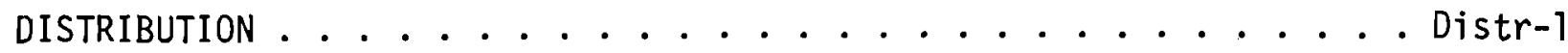




\title{
ENVIRONMENTAL SURVEILLANCE FOR FUEL FABRICATION PLANTS
}

\author{
J. P. Corley, D. A. Waite, J. W. Johnston, \\ and L. C. Schwendiman
}

\section{INTRODUCTION}

1. Purpose and Scope

This report is intended to provide source material, with rationale, which may be used for:

a) Preparation of a regulatory guide concerning environmental surveillance programs for sich facilities;

b) Evaluation of those portions of environmental statements for fuel fabrication facilities pertaining to proposed environmental surveillance programs.

Included is an environmental surveillance program sufficiently general to cover plants fabricating uranium oxide or mixed uranium and plutonium fuels. Program content is not specific to a particular plant. It must be emphasized, however, that facility design, including provisions for effluent control, may well influence the extent and scope of the environmental surveillance program for a specific plant, as will local geography, climate, and land usage. The discussion of equipment, measurement techniques, and quality control procedures, although believed to represent current technology, is also subject to change as technological improvements become available.

The proposed program provides for surveillance of media believed either to be significant in terms of dose to man or to be potential centers for long-term accumulation of contaminants. It is intended that reliance on outside agencies for routine data needs would be only for services to be contracted for by the licensee. Specifically excluded from this study is monitoring of plant effluents at the point of release.

In order to avoid the excessive duplication which would result from complete treatments of uranium and mixed oxide plants separately, 
BNWL-1723

discussion of the proposed program is presented mainly in terms of plutonium. The program is, however, equally applicable to both uranium and mixed oxide plants, with recognized points of divergence being pointed out and discussed.

There is no intent to provide a surveillance program adequate for all potential non-routine or accidental releases, although the proposed program will be useful in evaluating most lapses of control. For the true emergency situation, involving sudden major releases from events such as criticality, fire, and explosion, and requiring prompt emergency actions to minimize public risk, special surveillance requirements would apply. Further guidance should be provided independent of this study for such events.

2. Environmental Surveillance Rationale

Although many statements have been prepared as to the objectives of an environmental surveillance program for nuclear facilities those given below below are generally recognized as valid. The latter statements are taken from ICRP No. $7 .(28)$

a) Detection of sudden changes and evaluation of long-term trends of concentrations in the environment, with the intent to detect failure or Tack of adequate control of releases and to initiate appropriate actions.

b) Assessment of the actual or potential exposure of man to radioactive materials or radiation present in his environment, or the estimation of the probable upper limits of such exposure.

c) Determination of the fate of contaminants released to the environment, especially with the intent of detecting previously unconsidered mechanisms of exposure.

d) Demonstration of compliance with applicable regulations and legal requirements concerning releases to the environment. 
For protection of the public, these varying purposes are listed in order of relative importance. However, the time-lag and generally more diffuse effects that are inherent in environmental measurements make primary reliance on any environmental measurement as an action signal unwise. With the exception of long-term accumulations of contaminants from source terms too dilute to be measured, all environmental measurements should be considered as supplementary insofar as action guides are concerned, with primary (and possible secondary) action warnings from effluent or facility interior measurements.

3. Terminology

It will be helpful in the ensuing discussion to remember the authors' use of certain terms.

Monitoring - should be taken to mean continuous measurement of one or more contaminant concentrations or radiation intensity by direct or indirect means.

Continuous Sampling - includes both non-interrupted sampling and repetitive aliquots of a sampled medium obtained automatically at intervals much shorter than the interval between sample retrieval and analysis.

Composite Sampling - indicates discrete sample retrieval, with one or more measurements made on a composite of complete samples or of aliquots taken in the laboratory from each sample.

Minimum Analytical Detection Limit - means the minimum sample nuclide concentration distinguishable from a blank sample at an acceptable level of confidence. This limit is affected by chemical, physical and radiological counting limitations of the analytical laboratory and may be used as a basis for contractual performance criteria. 
Environmental Detection Limit - means the environmental sample nuclide concentration distinguishable from a background sample at an acceptable level of confidence. This limit is affected by the minimum analytical detection limit as well as the variability in the environmental media and in the sampling procedure.

II. STANDARDS AND CRITERIA

Basic radiation exposure criteria and radioactive effluent release criteria applicable to population exposure are given in 10CFR20 (extracted in Appendix A). Measurement techniques must be selected with the intent of being able to respond to comparisons with applicable standards. The intent is to be able to distinguish concentrations and doses at least as low as $1 \%$ of the specific criteria.

For non-radioactive contaminants, the most restrictive of the several Water Quality Criteria provided by the Federal Water Quality Administration

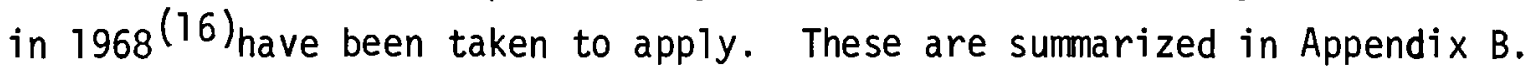
For airborne non-radioactive pollutants, no similar authoratitive listing is available, with the exception of the few national ambient air quality standards 1 isted by the Environmental Protection Agency. ${ }^{(6)}$ This 1 ist does include the oxides of nitrogen, one of the potential contaminants from a fuel fabrication facility. For the other most likely airborne contaminant, fluorides, applicable criteria summarized by the American Industrial Hygiene Association ${ }^{(9)}$ have been assumed to apply. Included are considerations of crop damage and fluorosis in grazing animals, both of which appear to be more limiting than inhalation by people per the latest edition of Threshold Limit Values. ${ }^{(66)}$ In any case, local or state air quality criteria presumably would apply. An example of individual state criteria which have been accepted by the U.S. Environmental Protection Agency as adequate are the Washington State Air Quality Criteria given in Appendix $B$. 


\section{SURVEILLANCE PROGRAM}

The surveillance program provides an operational system with rationale and preoperational system upon which the operational will be based. Except for instances which are discussed later in the preoperational section, the procedures for the preoperational phase are the same as described below.

1. Program Basis

The basis for the proposed environmental surveillance program incorporates the following assumptions:

a) Plutonium is the critical nuclide for a11 potential routine and transient releases.

b) Airborne releases of the radioactive contaminants are particulate in nature or are attached to filterable particulates.

c) Radioactive contaminants generally are of most concern in the evaluation of process material released to the environment, although in uranium oxide fuel plants the release of toxic chemicals may be the predominant factor.

d) Feed material characteristics of power reactor fuels for the next fifteen years obviate the monitoring of direct gamma exposure in the environment from normal fuel fabrication plant releases.

The program includes sampling of potential routine and transient releases in pertinent media at the facility boundaries, at points of suspected build-ups, at the nearest identifiable points of potential individual and population exposure to process contaminants, and in critical exposure pathways as indicated in Figure 1. It excludes the measurement of effluents and conditions within the facility buildings.

2. Critical Pathway Analysis and Calculation

To aid in meeting the scope and purposes of the proposed surveillance program above, the critical exposure pathway diagram shown in Figure 1 was developed. 


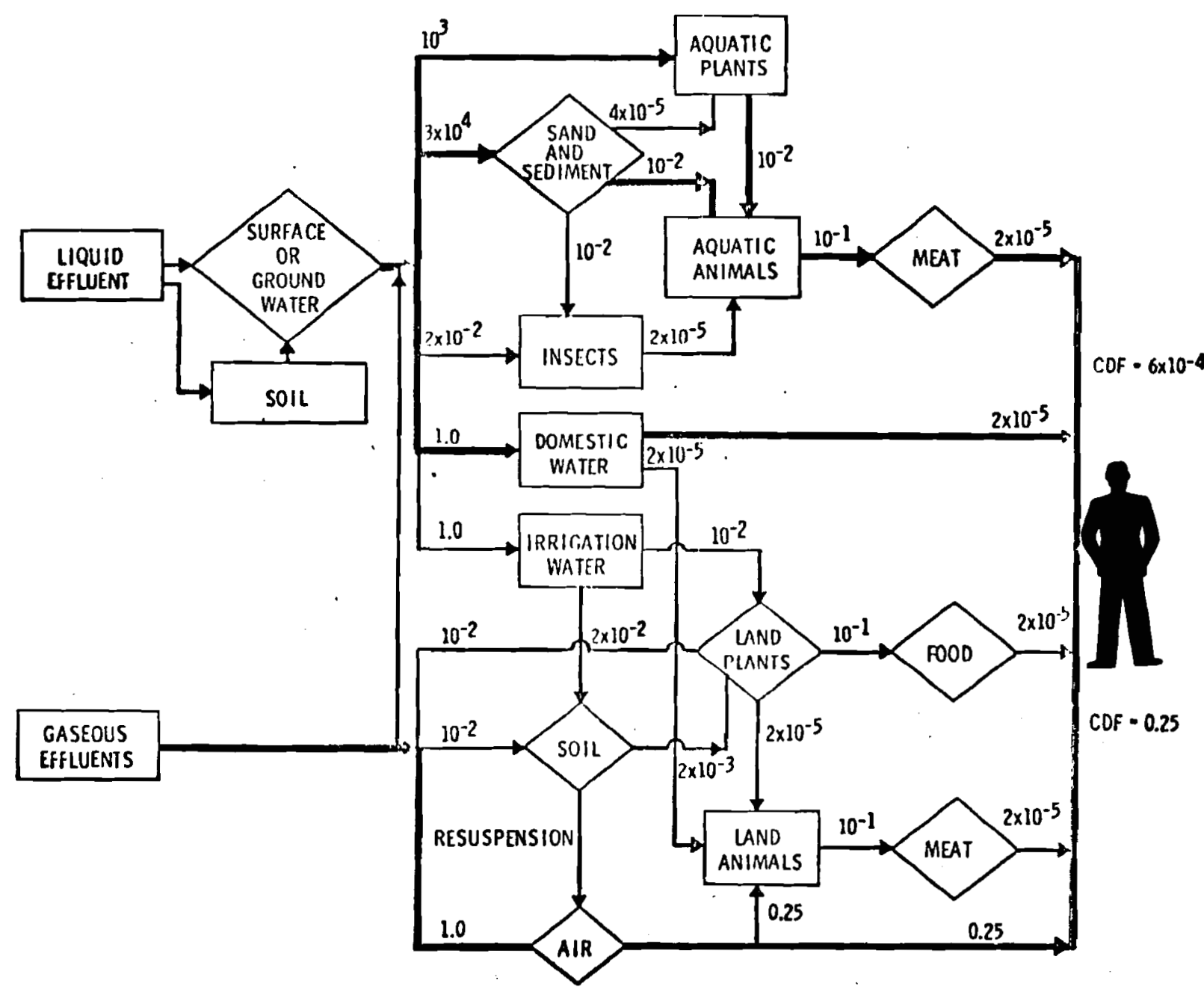

FIGURE 1: Discrimination Factors for Plutonium in the Biosphere 
This diagram helps to locate pertinent environmental media, points of expected long-term contaminant accumulations, and points of populationcontaminant interfaces. The chart has been constucted using available data on the transport of plutonium through the environment. The same pathways will be involved where uranium is the contaminant; even though the values are not precisely applicable to uranium transport, they are sufficiently similar that the conclusions drawn are the same.

Media appearing inside diamond shapes are media that should be sampled in the proposed surveillance program. Individual discrimination factors (IDF), defined as $(\mathrm{pCi} / \mathrm{g})_{\text {Recipient }} \div(\mathrm{pCi} / \mathrm{g})_{\text {Donor, }}$ or as the fraction of incident contaminant retained by recipients, are provided for each medium to medium transfer link. Identification of the critical exposure pathways was made by calculating the combined discrimination factor $(C D F)=\prod_{i=1}^{n}(I D F)_{i}$ for each recognized potential transport route from effluent release to human exposure.

Needed factors which are not available from the literature were calculated as shown in Table I. Two similarity assumptions are noted. The first is that bottom-feeding aquatic animals exhibit the same IDF toward their sources of nourishment as do plant-feeding aquatic animals. The similarity of the irrigation water $\rightarrow$ soil $\rightarrow$ land plant pathway and the sediment $\rightarrow$ aquatic plant pathway is the second assumption. In addition, an IDF of $2 \times 10^{-5}$ is assigned to most animal ingestion processes, ${ }^{(36)}$ surface contamination mechanisms are assigned $10^{-2}$, and food processing is assigned $10^{-1}$ after Langham. Other procedural steps in Table 1 note work by Soldat and Noshkin. Exposure routes with CDF's greater than $10^{-5}$ are regarded as potentially critical pathways and those with factors less than $10^{-15}$ are eliminated from consideration on the potential exposure pathway diagram. The four critical pathways are indicated by heavy lines on the chart. The largest CDF's for liquid and gaseous release routes are shown at the right of the figure. 


\section{TABLE I}

$$
\begin{aligned}
& \text { Water } \rightarrow \text { Aquatic Plants } \rightarrow \text { Aquatic Animals }=10 \quad(60) \\
& \text { Water } \rightarrow \text { Aquatic Plants }=10^{3} \\
& \text { Aquatic Plants } \rightarrow \text { Aquatic Animals }=10^{-2} \\
& \text { Sand and Sediment } \quad \rightarrow \quad \text { Aquatic Animals }=10^{-2} \quad(a) \\
& \text { Water } \rightarrow \text { Sand and Sediment } \rightarrow \text { Aquatic Animals }=300 \\
& \text { Water } \rightarrow \text { Sand and Sediment }=3 \times 10^{4} \\
& \text { Irrigation Water } \rightarrow \text { Soil } \rightarrow \text { Land Plants }=4 \times 10^{-5}(36) \\
& \text { Sand and Sediment } \rightarrow \text { Aquatic Plants }=4 \times 10^{-5} \text { (a) } \\
& \text { Soil } \rightarrow \quad \text { Land Plants }=2 \times 10^{-3}(60) \\
& \text { Irrigation Water } \rightarrow \text { Soil }=2 \times 10^{-2} \\
& \text { Soil } \rightarrow \text { Air } \\
& =10^{-2} \\
& \text { Air } \rightarrow \text { Man } \\
& =0.25 \\
& \text { Soil } \rightarrow \text { Air } \rightarrow \text { Man } \\
& =0.25 \times 10^{-5} \\
& \text { Soil } \rightarrow \text { Air } \rightarrow \text { Land Animals } \\
& =0.25 \times 10^{-5} \\
& \text { Air } \rightarrow \text { Land Animals } \\
& =0.25
\end{aligned}
$$

(a) Similarity assumed. See text.

(b) Assuming uniform distribution $1 \mathrm{~cm}$ depth of soit. 
BNWL-1723

The relative importance of each potential critical pathway was assessed by weighting the CDF for each route with quantities related to (a) the relative amounts of credible contaminants available to that pathway via expected environmental release of process materials and (b) the relative extent to which human populations are exposed to each route. By this process the critical pathway was clearly identified as that providing direct inhalation of airborne material. Pathways involving domestic water and aquatic animal consumption are at least four orders of magnitude less significant.

\section{Statistical Applications}

Statistical procedures are used in environmental surveillance to give three kinds of information -- estimates of average concentration levels, hypotheses tests that concentration levels are below specified limits, and determination of real trends of concentration levels over a period of time.

\section{a) Estimates of Concentration}

It is difficult to determine accurately how much confidence should be placed in estimates of environmental concentrations without a knowledge of the environmental variability, the sampling variability, and the analytical variability. The size of any proposed environmental surveillance program will reflect the postulated or experienced variability of the environment and the transport medium. The application of these principles to the surveillance program discussed here is covered under each medium sampled. Individual sample and analytical variability are routinely tested as part of the quality control procedures; such testing, it is assumed here, will be done by the licensee or his agent. Replication (taking more than one sample) over time and place is required to estimate environmental variability. Replication of individual samples (taking more than one sample at each time and place) is required to estimate sampling variability. Replication of 
BNWL -1723

analyses (making more than one laboratory determination per sample) is necessary but not always sufficient to determine measurement variability because of problems such as nonuniform aliquots of heterogeneous samples.

The accuracy and precision of the annual mean concentration estimates are also dependent upon how the samples are handled after they are collected. They are thus dependent upon the sample handling and analytical procedures used locally and are usually estimatable through laboratory quality control studies. Care in following written sample handling and analytical procedural guides can help improve accuracy, and duplicate analyses of each sample can improve precision of estimation.

Validity of the annual mean concentration estimate is mainly dependent upon the sampling procedures used, in the sense that the sampling apparatus should be capable of capturing the material that contains the nuclides of interest. It is assumed that the analytical procedures are capable of measuring the concentration levels of the isotopes of interest.

The required minimum analytical detection level (MADL) should be $2 x \sqrt{\text { Background }}$ for each nuclide-medium combination. The background count rate should be determined seasonally in the preoperational survey for each nuclide-medium combination. Individual detection levels must be established for each nuclide-medium combination in keeping with requirements for execution of the "P\%" analysis for program adequacy (see Appendix D). It is realized that this procedure may result in different MADL's for each fuel fabrication site. However, it is a highly desirable approach considering the great geographical, geological and climatological differences in existing plant sites. Greater sensitivities may also be required of facilities in low background areas, but this will most likely be offset in areas of higher background by the necessity for better statistical accuracy for discrimination of plant sources. For existing facilities, in the absence of any preoperational data, sensitivities should correspond to the lowest levels technically and economically practical (see Appendix $\mathrm{C}$ ). Revisions of MADLs may be necessary from time to time if indicated by results of samples from "unaffected areas." 
b) Tests of Hypotheses and Trends

Tests of hypotheses require an estimate of the sampling and analytical variability and an assumption about the form of the statistical distribution of the population of values of interest, except when nonparametric statistical tests are used. In the absence of specific knowledge or information to the contrary, the assumption that environmental data follows a log-normal distribution may be made. Similarly, trend lines, composed of estimates of time and/or place concentration levels, require estimates of variability to convey the degree of confidence to be placed in them.

Variability and bias for environmental sources are high compared to that attainable in controlled laboratory experiments or even in measurements for accountability control of nuclear materials. Since the levels to be measured approach the detection limits of the instruments used, this inherently poor measurement precision and accuracy. will be difficult to improve in most areas except by taking larger and larger samples. This approach may be costly and impractical. The environmental variability is uncontrollable, but its effect on statistical estimates and tests of hypotheses can be reduced by careful design of the sampling scheme.

4. Program Description

Important program characteristics are provided in Table 2. It should be emphasized that the analytical methods listed are equally applicable in uranium, plutoniun or mixed oxide fuel fabrication facilities. In a 11 cases an attempt has been made to utilize, on a minimum feasible frequency, techniques which offer the best available results. No portion of the program is intended to be exclusive to any needed additions.

a) Air Surveillance

(1) Equipment

Specific suggestions in Table 2 and the following sections concerning sampling equipment are aimed toward achieving comparability of similar programs without sacrificing flexibility or stifling individual ingenuity. 


\begin{tabular}{|c|c|c|c|}
\hline Type of Sample & Sampling bcations & Analytical Frequency* & Analyses \\
\hline \multirow[t]{2}{*}{ Air Particulate } & $\begin{array}{l}\text { (a) Plant boundary: (b) Maximum Concentration } \\
\text { points; (c) Population Centers; (d) Unaffected } \\
\text { areas. }\end{array}$ & Biweekly & alpha scan \\
\hline & Minimum weekly volume sampled $-i .5 \times 10^{4} \mathrm{ft}^{3}$ & & \\
\hline \multirow[t]{2}{*}{ Air - Gaseous } & Fluoride (1/me) paper at air sampling locations & $\begin{array}{l}\text { Monthly inspection } \\
\text { Intermittent analysis } \\
\text { Continuous sampling }\end{array}$ & $\begin{array}{l}\text { Visual inspection } \\
\text { Intermittent analysis }\end{array}$ \\
\hline & 0xides of nitrogen at plant boundaries & $\begin{array}{l}\text { Monthly } \\
\text { Intermittent sampling }\end{array}$ & ${ }^{N O}{ }_{x}$ \\
\hline \multirow[t]{3}{*}{ Surface Water } & (a) Upcurrent & $\begin{array}{l}\text { Monthly } \\
\text { Grab Sampling }\end{array}$ & alpha scan, $\mathrm{F}^{-}, \mathrm{NO}_{3}^{-}, \mathrm{NH}_{3}$ \\
\hline & (b) At outer edge of mixing zone & $\begin{array}{l}\text { Monthly } \\
\text { Continuous Sampling }\end{array}$ & alpha scan, $\mathrm{F}^{-}, \mathrm{NO}_{3}^{-}, \mathrm{NH}_{3}$ \\
\hline & $\begin{array}{l}\text { (c) First point of withdrawal for domestic } \\
\text { uses - continuous sampling }\end{array}$ & $\begin{array}{l}\text { Heekly } \\
\text { Continuous Sampling }\end{array}$ & Gross alpha, $\mathrm{F}^{-}, \mathrm{NO}_{3}^{-}, \mathrm{NH}_{3}$ \\
\hline \multirow[t]{2}{*}{ Groundwater } & Downgradient wells in use within 1 mile & Semi-annually & alpha scan, $\mathrm{F}^{-}, \mathrm{NO}_{3}^{-}, \mathrm{NH}_{3}$ \\
\hline & Selected wells in use between 1 and 5 miles & Annually & alpho scan, $\mathrm{F}^{-}, \mathrm{NO}_{3}^{-}, \mathrm{NH}_{3}$ \\
\hline Sed Iment & $\begin{array}{l}\text { Immed late downcurrent of discharge; downcurrent } \\
\text { at first impoundment }\end{array}$ & Semi-annually & alpha scan \\
\hline \multirow{2}{*}{$\begin{array}{l}\text { So11 and } \\
\text { Vegetation }\end{array}$} & Most air sampling locations & Semi-annually & alpha scan, $F^{-}$ \\
\hline & Nearest lands used to raise food crops & Monthly during growing season & $F^{-}$on washed grass \\
\hline $\begin{array}{l}\text { Aquatic anlmals, } \\
\text { Fish and Water- } \\
\text { fowl }\end{array}$ & As avaflable within 10-15 m!les of factlity & Semi-annually or annually & alpha scan \\
\hline Food crops & Nearest land used to ralse crops & Monthly during growing season & alpha scan \\
\hline $\begin{array}{l}\text { Deposition } \\
\text { Collactors }\end{array}$ & Selected air sampling locat!ons & Monthly & alpha scan \\
\hline $\begin{array}{l}\text { Terrestrial } \\
\text { Blota }\end{array}$ & As avallable within 10-15 miles of factlity & $\begin{array}{l}\text { Quarterly; semi-annually, or } \\
\text { annually - mostly during hunting } \\
\text { season }\end{array}$ & $\begin{array}{l}\text { alpha scan, } F^{-} \text {on bone, liver, } \\
\text { kidney of rabbits, large manmal } \\
\text { rodd-k11ls or game antmals }\end{array}$ \\
\hline
\end{tabular}

TABLE 2. Recommended Environmental Surveillance Program for a Fuel Fabrication Plant 
Likewise, comments on sampling techniques are intended to render help where needs have been indicated.

(2) Radionuclides

The final selection of equipment required for air sampling will depend somewhat upon the means by which the $1.5 \times 10^{4} \mathrm{ft}^{3} / \mathrm{wk}^{*}$ recommendation is accomplished. Satisfactory options vary from collecting $1.5 \mathrm{ft}^{3} / \mathrm{min}$. continuous $1 \mathrm{y}$ to collecting $30 \mathrm{ft}^{3} / \mathrm{min}$ intermittently for a total of $8.33 \mathrm{hrs} / \mathrm{wk}$. However, it should be emphasized that intermittent sampling should be related to representative plant operations and to meteorological conditions which will make possible valid interpretation of the resulting data.

In other respects, environmental air monitoring equipment should meet the following criteria:

1. Direct sampling with no lines upstream of the sample medium is recommended.

2. The sample collector should be easily readable in place with portable monitoring instruments and removable for subsequent Taboratory analysis.

3. The instrument system should be protected from the external environment, including blowing dust, precipitation, high winds, and extremes of temperature.

4. To insure proper calibration, operation and interpretation, a fixed volume sampler should be used. Sampling rate should remain constant within $+25 \%$ during the normal operating period.

5. The unit should be compatible with standard glass fiber and cellulose fiber filters commonly used for air sampling. Under expected conditions the filter media should have an efficiency not less than $99.5 \%$ for particles $0.3 \mu \mathrm{m}$ in diameter and should permit $75 \%$ recovery of the collected pollutant. Examples of satisfactory collection media are MSA-1106B,

*This volume was found to be easily attainable with presently available equipment and yields sufficient sample material to provide satisfactory minimal analytical detection limits. 
Millipore AA and RA, Microsorban, Gelman AM-4, and HV-70 filter paper.

6 . Air flow rate should be continuously indicated by an appropriate, clearly marked gauge having an accuracy of $\pm 20 \%$.

\section{(3) Fluorine Compounds}

A potential exists for emissions of gaseous and particulate fluorine compounds from nuclear fuel fabrication plants. The primary source of fluorine is the starting compound $\mathrm{UF}_{6}$ which is converted to uranium oxide. One process hydrolyzes the $\mathrm{UF}_{6}$ in water and precipitates ammonium diuranate, which is then separated, dried and calcined to the oxide.

During the calcining process, gaseous compounds of fluorine and inorganic fluoride particles should be evolved in relatively small amounts. With normal scrubber efficiency on the off-gases, less than 400 grams (as fluorine) per day should be released to the atmosphere by a plant producing one tonne of fuel per day. A uniform release rate of $400 \mathrm{~g} /$ day from a $30 \mathrm{~m}$ stack would produce a maximum ground concentration $^{(59)}$ of about $1.5 \times 10^{-7} \mathrm{~g} / \mathrm{m}^{3}$ with a $5 \mathrm{~m} / \mathrm{sec}$ wind and slightly unstable air stability. From comparison with the fluoride standards referenced (Appendix $B$ ), it is not considered likely that fluoride levels released from the reference plant would be of great concern. There may be occasional episodes of off-standard operations which would momentarily increase levels.

The Washington State Airborne Fluoride Standards (shown in Appen$\operatorname{dix} B$ ) appear to be consistent with the experimental data and the concentrations cited as acceptable for most plant species, ${ }^{(61)}$ al though it has been noted that unique circumstances may exist in which the values may be either over- or under-protective. ${ }^{(24)}$ flora are frequently categorized in three classes as to sensitivity to atmospheric fluoride or tissue concentrations: susceptible, intermediate, and tolerant species. However, it is recognized that differences in tolerance by individual species within each grouping is great and dependent on a number of variables, including climate, soil and chemical state. In a review ${ }^{(44)}$ of current information on the concentrations 
of gaseous fluoride in air causing foliar markings, threshold levels were described as: (1) $3-4 \mu \mathrm{g} / \mathrm{m}^{3}$ for the most susceptible species and $10 \mu \mathrm{g} / \mathrm{m}^{3}$ or higher for species of intermediate susceptibility, for exposures of one day; and (2) for exposure periods longer than a month, about $0.5 \mu \mathrm{g} / \mathrm{m}^{3}$ for susceptible and between $1-3 \mu \mathrm{g} / \mathrm{m}^{3}$ for some intermediate species. It was also noted that although the relationship of accumulated foliar fluoride to the occurrence of lesions is complex, susceptible plant species show foliar lesions when tissue fluoride concentrations range from 20-150 ppm. Other considerations, especially that of effects of fluorides on animals via feed crops such as alfalfa, should also be covered by the limits shown in Appendix $C$.

The recommended sample collector for airborne fluorides is ashless filter paper (e.g. Whatman No.40), impregnated with a saturated $\mathrm{Ca}(\mathrm{OH})_{2}$ solution, then dried. The filter paper is supported in a filter holder and air drawn through at the required rate $(1.5 \mathrm{cfm}$ for a 2 " diameter filter or about 6-10 cfm for a 4" diameter filter. Duration and volume rate of samples should be determined by experimentation to achieve an optimum $\mathrm{F}^{-}$content in the sample. To measure with confidence 0.1 $\mu \mathrm{g} / \mathrm{m}^{3}$ of $\mathrm{F}^{-}$would then require sampling about $100 \mathrm{~m}^{3}\left(\sim 3500 \mathrm{ft}^{3}\right)$ of air.

At the end of the sampling period the filter is carefully folded with the collection surface inward and delivered to the laboratory. The filter paper is placed in a platinum, nickel, or Inconel crucible and moistened. The filter is ignited at $550-600^{\circ} \mathrm{C}$ to destroy all carbonaceous material, then fused with sodium hydroxide. The melt is cooled and dissolved in a few $\mathrm{ml}$ of water. Hydrogen peroxide $\left(\mathrm{H}_{2} \mathrm{O}_{2}\right)$, in $30 \%$ solution, is added and the solution boiled to remove excess $\mathrm{H}_{2} \mathrm{O}_{2}$. The solution is transferred to a polyethylene, teflon, or polypropylene beaker. The alkaline sample is diluted 1:1 with a combined buffer, ionic strength adjuster, and complexing agent, and adjusted to pH 5.9-6.1. A fluoride-ion-sensitive electrode is inserted in the solution and the potential corresponding to the fluoride ion concentration is measured in millivolts. (31) Temperature is controlled to $\pm 2^{\circ} \mathrm{C}$ and a11 solutions are stirred during analysis. A calibration curve of millivolts versus fluoride-ion concentration obtained under identical 
conditions is used to convert the millivolt reading to $\mu \mathrm{g} \mathrm{F}^{-}$per $\mathrm{ml}$ of final solution.

The range of measurement is from $0.019 \mu \mathrm{g}$ fluoride ion per $\mathrm{ml}$ of solution, ${ }^{(17)}$ but the recommended range is between 0.1 and $10 \mu \mathrm{g} / \mathrm{ml}$.

The electrode method of fluoride analysis of water samples was found to compare favorably with the ion-exchange calorimetric method. (38) The relative standard deviation ranged from 2.9 to $5.8 \%$ and relative errors of 0.2 to $4.9 \%$ were found. Use of complexing agents significantly reduced the negative errors caused by the presence of aluminum.

(4) Compounds of Nitrogen

Two contaminants potentially released from the process are ammonia, $\mathrm{NH}_{3}$, and nitrogen dioxide, $\mathrm{NO}_{2}$.

Ammonium hydroxide is used to convert the hydrolyzed $U F_{6}$ to ammonium diuranate. Significant quantities of ammonia will be generated from the subsequent thermal reduction of the ammonium salt, but with efficient scrubbers in the system not more than about $3 \mathrm{lb} /$ day should appear in the airborne effluents of a one tonne/day plant. The resulting maximum downwind concentration near the ground would be on the order of $0.4 \mu \mathrm{g} / \mathrm{m}^{3}$, if uniform release is assumed. The Threshold Limit value is $35 \mathrm{mg} / \mathrm{m}^{3}$, five orders of magnitude greater than that estimated to be present with the assumptions used.

In the conversion of plutonium nitrate to plutonium oxalate, nitric acid is formed. The precipitated plutonium oxalate is removed, carrying a small quantity of nitric acid. The oxalate is calcined in a stream of hydrogen, yielding $\mathrm{PuO}_{2}, \mathrm{CO}, \mathrm{CO}_{2}$, and $\mathrm{NO}_{x}$ from the carryover of acid.

The evolution of nitrogen oxides solely from normal calcining of $\mathrm{Pu}\left(\mathrm{NO}_{3}\right)_{4}$ to the oxide should be of little significance. For a one tonne uranium per day plant producing a $96 \% \mathrm{UO}_{2} .4 \% \mathrm{PuO}_{2}$ fuel, about 44 pounds of plutonium or about 108 pounds of $\mathrm{Pu}\left(\mathrm{NO}_{3}\right)_{4}$ will be calcined daily. The $\mathrm{NO}_{2}$ evolved would be about 7 pounds/day. If this were released uniformly in a five $\mathrm{m} / \mathrm{sec}$ wind, under slightly unstable 
meteorological conditions, the downwind concentration (59) would be about $1 \times 10^{-6} \mathrm{~g} / \mathrm{m}^{3}$. The national ambient air standard ${ }^{(6)}$ for $\mathrm{NO}_{2}$ is about $100 \mu \mathrm{g} / \mathrm{m}^{3}$, or two orders of magnitude greater than that estimated. The Threshold Limit Value is $9000 \mu \mathrm{g} / \mathrm{m}^{3}$. (66) However, other sources of $\mathrm{NO}_{x}$, such as scrap recovery operations, may provide higher effluent concentrations.

The recommended system for monitoring $\mathrm{NO}_{x}$ is a continuous chemiluminescent analyzer, available commercially from several manufactures. In this system the detection of oxides of nitrogen depends upon the reaction:

$$
\mathrm{NO}+\text { Ozone } \rightarrow \mathrm{NO}_{2}+1 \mathrm{ight}
$$

The light (chemiluminescence) is sensed and measured with a photomultiplier tube and recorder.

The analyzer should sample the air to be tested with a pump which can be adjusted to give the desired flow rates arid a flowmeter with an accuracy of $\pm 5 \%$ of full scale. The sample line and the cell should be of glass or teflon. An oxygen supply and ozone generator with an oxygen consumption of about $200 \mathrm{ml} /$ minute must be provided with a flowmeter showing oxygen flow to $\pm 5 \%$. Some provision for destroying excess ozone in the exhaust stream is required to reduce the ozone concentration to $<20 \mathrm{ppb}$. Any $\mathrm{NO}_{2}$ present must first be reduced before ozone is added in the reaction cell in which the light is measured. A reducing column in the inlet is provided to reduce $>95 \%$ of $\mathrm{NO}_{2}$ to $\mathrm{NO}$.

The instrument should have a range of up to $2 \mathrm{ppm}$, with manual range selection; the minimum detectable concentration of $\mathrm{NO}_{x}$ should be $2 \mathrm{ppb}$. Ninety percent of the equilibrium reading should be attained within 10 seconds following an instantaneous concentration change. Zero drift should not exceed $1 \%$ of ful1 scale in 24 hours. Accuracy of $\pm 2 \%$ should be demonstrated with known concentrations of $\mathrm{NO}_{2}$.

The instrument should operate from $115 \mathrm{~V} \mathrm{A.C.} \mathrm{power.} \mathrm{It} \mathrm{should}$ operate satisfactorily in temperatures from $-30^{\circ} \mathrm{C}$ to $+50^{\circ} \mathrm{C}$ and 
BNWL-1723

relative humidity from 20 to $100 \%$, or else provision should be made for heating or cooling the shelter in which the instrument is to operate. Temperature should be maintained through a thermostat which will control housing temperatures such that the sensitivity, accuracy, and stability criteria will be achieved.

\section{(5) Sample Locations}

The sampling technique should be designed to take representative samples of radionuclides or non-radioactive materials in the ambient air. The preferred sampling location is at one meter above ground level, in a location free from unusual micrometeorological or other conditions (e.g., proximity of large buildings, vehicular traffic) which could result in artificially high or low air concentrations.

Distances of sampling locations from release points should be selected to correspond to (a) plant boundaries, (b) maximum concentration points, (c) population centers, and (d) unaffected areas. Radial partitioning of sampling locations on an octant basis may be determined by calculating

$$
\text { Weighting Factor }=\frac{\text { fraction of total population }}{\text { distance }}+\begin{gathered}
\text { fraction of time } \\
\text { downwind from source }
\end{gathered}
$$

The "fraction of time downwind" term is included since the airborne contaminants must be carried to the population before an inhalation hazard exists. The probability of a human exposure is, therefore, the sum of the probabilities of having a population present and having the contaminant available. An isotropic mean wind speed is assumed, but departures from this assumption have no significant effect on results of the distribution analyses. The expected total of sampling locations would be 10-15 to provide adequate geographical coverage. The sum of eight calculated weighting factors would be scaled so as to equal the total number of sampling locations. This scaling factor when multiplied by each individual octant weighting factor would yield the number of sampling sites within that particular octant, when rounded to the nearest integer. 
The method is illustrated by the following example:

Data :

1. Cities

\begin{tabular}{|c|c|c|c|}
\hline $\begin{array}{l}\text { Direction } \\
\text { From Source } \\
\end{array}$ & Population & $\begin{array}{l}\text { Distance } \\
\text { From Source } \\
\end{array}$ & $\begin{array}{l}\text { Fraction } \\
\text { Total Population }\end{array}$ \\
\hline NW & 50,000 & 2 miles & .5 \\
\hline SW & 30,000 & 6 miles & .3 \\
\hline$E$ & 20,000 & 10 miles & .2 \\
\hline
\end{tabular}

2. Annual average wind rose

\begin{tabular}{rc}
$\begin{array}{c}\text { Direction } \\
\text { From Source }\end{array}$ & $\begin{array}{c}\text { Fraction of Time } \\
\text { Downwind of Source }\end{array}$ \\
\cline { 2 - 3 } N & .20 \\
NW & .15 \\
W & .00 \\
SW & .15 \\
S & .10 \\
SE & .10 \\
E & .20 \\
NE & .10
\end{tabular}

3. Total of 15 air sampling locations

\begin{tabular}{|c|c|c|c|c|c|}
\hline $\begin{array}{c}\text { Direction } \\
\text { From Source } \\
\end{array}$ & $\begin{array}{c}\text { Fraction of } \\
\text { Population } \\
\text { Distance } \\
\end{array}$ & $\begin{array}{c}\text { Fraction of } \\
\text { Time } \\
\text { Downwind } \\
\end{array}$ & $W$ & $\begin{array}{c}\text { Scaled } \\
\mathrm{W}\end{array}$ & $\begin{array}{l}\text { Number of } \\
\text { Samplers }\end{array}$ \\
\hline$N$ & 0 & .20 & .20 & 2.28 & 2 \\
\hline NW & .25 & .15 & .40 & 4.56 & 5 \\
\hline W & 0 & 0 & 0 & 0 & 0 \\
\hline SW & .05 & .15 & .20 & 2.28 & 2 \\
\hline$S$ & 0 & .10 & .10 & 1.14 & 1 \\
\hline SE & 0 & .10 & .10 & 1.14 & 1 \\
\hline$E$ & .02 & .20 & .22 & 2.5 & 3 \\
\hline \multirow[t]{2}{*}{$\mathrm{NE}$} & 0 & .10 & .10 & 1.14 & 1 \\
\hline & & & 1.32 & & 15 \\
\hline
\end{tabular}

Scaling factor $=\frac{15}{1.32}=11.4$ 


\section{(6) Sample Collection and Analysis}

The analysis and collection frequencies given in Table 2 relate only to periods with release rates less than investigatory levels. If routine releases are greater than normally anticipated, these frequencies may have to be increased to properly evaluate regulatory compliance. The bi-weekly air sampling period is aimed at the elimination of more frequent analyses yielding less useful information than the alpha scan technique, while not exceeding a sampling period difficult to achieve with available equipment and potential dust loading on the filter media.

As far as practicable, all radioactive sample media should be treated identically. For plutonium and uranium, sample preparation could include either a media fusion or leaching process followed by electrodeposition and alpha scanning. A procedure, adapted from Chu ${ }^{(4)}$ for soil but readily adaptable on other media, is widely used for plutonium. A possible alternative procedure to alpha scanning when uranium is the contaminant of major concern is a fluorometric analysis. (21)

The variability due to random fluctuations is either analytical process can be reduced through replicate analyses of sample aliquots and duplicate runs on the same aliquot, and by standardizing results with those obtained by using more precise analytical techniques.

Fluoride sampling with lime paper should be done at each air sampling location, so that they are exposed to the same ambient air as the particulate samplers. The 0 or 1 nature of the measurement resulting from visual inspection of the fluoride paper cannot provide a concentration estimate, and only cumulative exposures greater than a certain value are discernible. They should be visually inspected when filters are collected for analysis, and those which visually indicate fluoride absorption should be returned to the laboratory for further analysis.

Continuous monitoring for $\mathrm{NO}_{2}$ is indicated at the point of maximum concentration as estimated from meteorological data obtained during the preoperational survey. The data from the nitrogen oxide 
analysis can provide an estimate of the average annual level using the same calculational formulas as for the alpha scan results.

Only these two non-radioactive substances have been treated here because of the varied characteristics of the processes and the facilities being addressed by the proposed program. Specific facilities and processes may allow the deletion of one or both of these substances from the program but may also necessitate addition of other unlisted analyses.

\section{(7) Quality Controls}

Quality control mechanisms should be exercised for al1 procedures involved. The surveillance system operation should be checked at least quarterly and calibrated and remedial measures taken when indicated. Again, the baselines to which normal operation is to be compared should be established and validated during the preoperational phase where possible. For most procedures, quality control frequencies may be quarterly.

Sampling quality control may necessitate temporary reinstatement of some aspects of the preoperational procedure, e.g., multiple sampling, sample splitting, and varying sampling locations. Similar analytical quality assurance procedures are expected to be instituted, such as treating audit samples of known concentrations.

Counting instrument checks which should be made each day of use are (a) alpha peak locations for a two-peaked, active reference source, (b) counts in peak areas of reference source, and (c) background counts in channels of interest. It is assumed that a control chart method of data rejection or acceptance will be applied here. (12) Instrument calibrations should be run at least quarterly and following maintenance.

b) Water Surveillance

\section{(1) Surface Water}

The basic recommendations in this section are intended to be equally applicable to fuel fabrication facility sites bordering rivers, 
lakes, tidal zones or estuaries. In the latter locations substantial hydrological and surface flow data involving dye or plant releases, may be necessary to establish areas referred to in this section as background and maximum concentration sites. Once these locations are determined, however, the sampling techniques should parallel the program proposed here regardless of the facility location.

Surface water should be collected routinely at a representative unaffected location, at the edge of the effluent mixing zone, and at the nearest downcurrent point of withdrawal for domestic or other uses. Where experience and process design can assure that no direct or indirect release is made to surface waters, this segment of the surveillance program may be reduced.

The sampling regions can be considered to represent three statistical universes. The parameter to be estimated by samples from upstream is the environmental background concentration of the river. (Releases into lakes and oceans would be surveyed by sampling up current of the release). Assuming that background concentrations are uniform in the body of water, simple random samples from the four-dimensional sampling frame defined in terms of time, location, and depth would suffice. Monthly grab samples may be adequate to estimate annual average background level, but it would be desirable initially to have more frequent collection and analysis of samples to compare the variability with the weekly analyses from samples taken at the first point of withdrawal for domestic use. To help assure validity of the background estimate, the sampling location should be beyond the influence of any groundwater or airborne particulate releases.

The parameter to be estimated by samples from the mixing zone is the nuclide concentration in the water. The same type of four-dimensional sampling frame as for the upstream location should be used, but rather than using a simple random sample, multiple sampling based on diffusion and transport studies of the mixing zone may be necessary. Simple random sampling from the sampling frame will suffice if the frame is located downcurrent of the line of homogeneity of the mixing zone. 
The parameter to be estimated by samples from the first point of withdrawal for public use is the maximum amount of radioactivity in the water supply of any population group. Usually this will be the first farm or town downcurrent from the facility which draws water from the source. However, transport and diffusion studies should be reviewed to make sure that the nearest withdrawal point does obtain the greatest radioactivity, since transport anomalies could result in a more distant community drawing more highly radioactive water. This possibility is remote if the mixing zone is defined and if the first withdrawal is beyond the line of homogeneity.

The recommended sampling location is the user's inlet 1 ine since this will tend to maximize any dose estimates. However, samples of treated water may also be taken to determine any removal in the water treatment process and improve the accuracy of the dose estimates.

Recommended practice is automated continuous sampling. * Although not considered mandatory, it is desirable to take these samples with timing proportional to flow rate rather than to take systematic samples of constant volume. The resultant sample would be self-weighting and provide a statistically unbiased estimate of the time-averaged weekly concentration in the water pumped from the river. A knowledge of the variability over time of concentration and pumping rate could be used to optimize the sampling rate.

To insure sufficient volume for analysis and quality control, minimum 4-liter samples are recommended. Compositing of smaller sample volumes is acceptable if the resultant sample will be representative of local environmental levels. Whether this is necessary should be established in the preoperational survey. Pre-treatment of sample containers should be provided for any samples to be held for more than 24 hours, to halt biological activity and to minimize wall deposition.

*About $50 \mathrm{ml}$ frequently (about every half hour) during a week, compositing the samples for weekly analysis. 


\section{(2) Groundwater}

Three regions are also recommended for analys is of radioactivity in groundwater; on site, wells within one mile and five miles from the site.

Although pre-existing wells may not provide a random sample of the groundwater around the facility, the expense of drilling wells to estimate the average concentration of radionuclides in the groundwater can be prohibitive. However, systematic sampling (in time) of existing wells and a well drilled on-site, if necessary, can provide point estimates of concentration levels useful in monitoring trends. The frequency and location of wells to be sampled routinely must be determined from available knowledge of local groundwater conditions. The nearest well down-gradient on the water tables should be sampled. If no release is made to the ground and no evidence is found of plant sources in the nearest wells, no other samples may be necessary.

Groundwater sampling is usually grab sampling done by dipping or bailing. If anomolies appear, or a question exists as to groundwater flow patterns or contamination levels, more reliable results are obtained by pumping with a submersible pump, collecting samples at intervals. Local well-drillers, if knowledgeable for the site, can be of great assistance in planning and evaluating a groundwater program.

Sample size and container treatment should be the same as for surface water samples. However, the frequent chemical instability of groundwater samples makes it important to try to exclude air from the samples and to analyze as quickly as possible.

\section{(3) Sample Analysis}

Following sample preparation, the analyses of these 4-7iter water samples should proceed exactly as discussed in air sampling. Quality controls and requirements are similar.

Although routine analyses for only $\mathrm{F}^{-}, \mathrm{NO}_{3}^{-}$and $\mathrm{NH}_{3}$ are listed, the need for analysis of liquid wastes and, therefore, of surface and 
groundwaters for heavy metals, organic materials, or toxic chemicals, may become apparent. As with the air monitoring, suggested analyses for chemical contaminants are listed on the basis of probability; specific plant processes may indicate no need for these specific analyses.

Required chemical analyses can be made on samples from the same sampling points as listed for radioanalysis. For continuous samples, chemical treatment of collection jugs should be provided to improve reliability. The analytical frequencies recommended in Table 2 are designed to yield a maximum of useful data, consistent with established regulations, but as economically as possible.

\section{c) Surveillance of Other Media}

\section{(1) Foodstuffs}

The specific media which fall under this general heading are (a) aquatic animals and waterfowl, (b) food crops and (c) terrestial biota.

Aquatic animals (as discussed here) are any animal species which derive substantial portions of their nourishment from aquatic-based media, and which may either be part of a human food chain or show significant accumulation of radioactivity. Fish and invertebrates, as well as aquatic mammals, are of potential interest. Local diet intakes derived from hunting and fishing must be examined during the preoperational survey. Local sportsmen organizations, sporting goods dealers, and state fish and game departments all may provide useful information of this kind. In the absence of other information, interviews with the local population may establish locations, quantities, and species which are significant to the local diet and which should be included in the surveillance program. If no such biota are normally used or available as foodstuffs, smaller mamma1s, non-sports fish or invertebrates may be substituted.

For fresh produce and other crops, a local land-use study will almost certainly be necessary to determine what crops are important in 
BNWL-1723

the local diet and where they are produced with regard to facility. County extension agents will normally prove helpful. Processed items from commercial sources will be helpful in providing background data and minimizing the need for preoperational data.

A minimum 4-kg sample of the edible portions of foodstuffs should be taken in seasons corresponding to their consumption by humans. Sampling of all food items should be done as closely as possible in time to their actual consumption. Sample size and preparation for these media should provide at least 40 grams of ash from a representative sample; this can be further divided for isotopic analysis.

\section{(2) Soi1, Sediment, and Vegetation}

Soi 1

There is considerable diversity of practice in sampling and analyzing soil. The position taken here is that sampling under normal plant operating conditions should accurately determine recent trends in local environmental nuclide levels. In keeping with this objective, routine sarmpling of the soil surface (1/2 to 1 inch) is recommended, al though several cores to define depth distribution of nuclides are desirable during preoperational surveys. Core depths of 12 to 30 inches, analysed in 2 to 4 inch increments, may be necessary depending on local rainfall and tillage practices. Experience at the Hanford site has shown that sampling the top $1 / 2$ inch of soil is feasible with the proper technique and tools. However, in locations with heavy vegetation and high precipitation it may be necessary to take samples to a 2 inch depth to insure uniformity and complete recovery of recent contaminant depositions. Sampling locations should be adjacent to air samples and if possible, on or adjacent to land used to raise food crops. These locations should be free of excessive deposition or removal by wind action. On a square test plot of approximately $100 \mathrm{ft}^{2}$, 5 to 10 separate cylindrical samples of several inches in diameter may be composited to provide the requisite sample size of 200 grams dry. This sample size will permit duplicate analyses or aliquots as large as 100 grams. 
BNWL-1723

\section{Vegetation}

Vegetation samples may be taken in conjunction with soil samples in order to obtain a better estimate of total deposition, or may be taken separately to measure availability of contaminants in food chains. Both purposes should preferably be met, but have different constraints. For estimates of deposition, especially accumulation over a period of time, perennial vegetation is perhaps the best choice. Forage on the other hand should be sampled at times of consumption by grazing animals.

For either purpose, sampling locations adjacent to air sample locations will permit better comparability. Samples of the same vegetation species at each location are desirable for the same reason.

Hand clippers are desirable for sampling, especially when collecting standing vegetation on soil sampling sites. A minimum of one kilogram of sample should be collected to provide the needed dry sample weight for desired analytical sensitivity. The analytical procedures will provide drying, weighing, and acid digestion, followed by analysis as an aqueous sample.

\section{Sediments}

As soil samples may provide a record of deposition from airborne releases, so stream sediments may provide a record of deposition from liquid releases. Plutonium especially is subject to siltation and immediate deposition at outfall locations, although stream flooding or changes in current patterns may cause scouring and redeposition of sediments at distant locations. Sediments should be sampled upcurrent and immediately downcurrent of the discharge and in rivers at the first impoundment downstream. Where no impoundment exists, as for discharges to lakes and estuaries, tracer studies may reveal most probable sites of sediment accumulation. In the absence of other information, stream obstructions, intake forebays, and even small embayments will act as collecting points for such accumulations. 
Some search may be necessary to avoid gravels or mixed deposits which are almost impossible to sample meaningfully.

Samples immediate downcurrent from the discharge will be used to estimate the initial contaminant concentration in sediments. Samples downcurrent at the first impoundment or embayment wil1 be used to estimate the maximum contaminant concentration from deposition. A sampling frame should be constructed for each target area and the sediment from at least two sub-locations, randomly selected for each sample period, should be analyzed separately. This sampling scheme will provide the estimates of variability required to make statistical comparison of trends.

Although simple scoops or clamshell dredges may be used for underwater sampling, the compaction that occurs slowly in underwater sediments and the washing that occurs during sample retrieval make coresampling most desirable for inventory of contaminants. For shallow, uncompacted layers, a vacuum corer may be needed. Sample cores may be sectioned to give better definition provided that each section can give a dry weight of about 200 grams.

Sample reduction and analysis should be the same as discussed under Air Surveillance.

\section{(3) Deposition Collectors}

As an indicator of ground-level deposition, resuspension of contaminated materials, and contaminant washout by precipitation, an array of combination dry trap-precipitation collectors is suggested for inclusion in the surveillance program.

The collector may consist of a nonmetallic funnel of approximately 6-3/4 inches radius at the top (approximately $1 \mathrm{ft}^{2}$ area). Clamped into the top of the funnel is a 1/4 inch thick disk of rigid rubberized fiber air conditioner dust filtering material. Under normal operating conditions no support grid should be needed beneath this filter mat. Attached to the stem beneath the funnel is a plastic bag which collects 
the precipitation if any occurs. The volume of this bag should be selected so it is capable of containing any anticipated amount of rainfall which might occur between sample collections. Owing to the wide range of annual precipitation levels around the country, flexibility in the collection frequency for these devices should be permitted.

The surface of the filter media may be surveyed directly with portable radiation instruments before removal and at any other time deposition is suspected. The weekly or post-precipitation collection will involve returning the filter, funnel and precipitation reservoir to the laboratory and replacement by clean components. The funnel wash and the precipitation sample should be handled as all other water samples. The filter mat contamination may be removed by treating the mat in an ultrasonic bath. In this way the contaminant can be suspended in an aqueous media for easy sample reduction and analysis. Cross-contamination of samples and apparatus must be carefully controlled. Rigid stands to hold the upright orientation of the device must be provided at each sampling site. If these stands are made of pipes of approximately 6 inches radius inserted in holes in the ground, the resultant deposition collector can be approximately at ground level.

Deposition-precipitation collectors should be placed at air sampling locations which correspond to either plant boundary or maximum calculated ground deposition points in the prevailing downwind directions. Background determinations should be made at points coinciding with background air sampling locations.

\section{Preoperational Program}

\section{a) Objectives}

Maximum realization of the design objectives and purposes of the environmental surveillance system necessitates extensive preoperational and/or facility-uninfluenced environmental data. The collection of 
data for the preoperational program begins with accumulation of knowledge about the area for the facility environmental statement. In addition to these data on hydrology, meteorology, geology, biology, etc., an aditional 18 to 24 months' data are needed to establish: (1) baseline environmental contaminant concentrations upon which future operational judgements may be based, (2) statistical levels of confidence in environmental surveillance results, and (3) quantities which are necessary in converting environmental concentrations to estimates of individual or population doses. In addition, this opportunity to evaluate the preoperational nuclide inventory should be seized.

As a starting point for program implementation, data available on nationwide ambient radionuclide levels may be used. These data, plus data generated by the preoperational survey will provide baselines from which trends can be established and data from which estimates of important statistical quantities can be derived. For fuel fabrication plants which are already in operation, it should still be possible to derive the needed statistical data.

The characteristics of the statisitical error structure involves the estimation of the sampling and measurement errors, both random (estimated by variances) and constant (estimated by biases). The variance of the sampling errors is estimatable through replication of the sampling apparatus at location-time points (e.g., multiple filters in juxtaposition). The variance of the measurement errors is estimatable through replicate analyses on separate aliquots from the same sample. The bias in the measurement system can be determined from analyzing blanks and pseudosamples spiked to a quantity of activity which is known with high accuracy and precision. The bias due to sampling is the most difficult to estimate. Some measurable biases due to sampling are derivable from: a) the known efficiency of filters, b) the flow rates through filters, c) the depth of soil samples and, d) studies of dispersion in receiving waters.

Appendix $D$ contains a statistical model for the observations obtained for a time/place point and a nuclide-media combination, and 
the outline of a plan for conducting the statistical characterization part of the preoperational survey.

In many cases different samples or more samples per unit time than planned for operation will have to be collected in order to obtain the statistical results needed from the peroperational program in a convenient time period. This is especially true since assessment of seasonal and statistical variations in nuclide content of samples are as important a part of a preoperational program as are the assessments of average concentrations.

Except for special instances pointed out in the statistics section, the sampling and analysis aspects of the preoperational sampling and analysis routines should be as nearly 1 ike those anticipated to be used during normal operation as possible. Experimentation in sampling locations may be desirable to establish the representativeness of subsequent operational samples. Throughout the preoperational phase, alertness to the possible importance of unusual critical pathways and populations should be maintained.

b) Checklist

Consolidating from the preceding sections the procedures and data which must be part of the preoperational survey, the following checklist is offered:

$\underline{\text { AIR }}$

1. Establish preoperational concentrations for process contaminants.

2. Establish seasonal variations in preoperational concentrations.

3. Establish meteorology for atmospheric dispersion calculations. WATER

1. Determine liquid effluent mixing patterns in receiving waters.

2. Establish nearest downgradient point(s) of groundwater usage.

3. Establish sampling sites which yield representative samples.

4. Establish locations of contaminant-population interfaces. 


\section{OTHER MEDIA}

1. Establish preoperational concentrations for credible contaminants in all media.

2. Establish points of suspected buildup.

3. Study dietary and cultural habits of local inhabitants.

4. Search for unusual critical exposure pathways.

5. Define locations of contaminant-population interfaces.

6. Establish soil and vegetation contaminant inventory.

\section{ALL MEDIA}

Establish statistics on sampling and analysis.

(a) Collect multiple samples at one location at one time.

(b) Run multiple analyses on aliquots of a single sample.

(c) Collect samples simultaneousiy at multiple sites.

A flow diagram for the previous recommendations on establishing statistics of sampling and analysis follows:

\begin{tabular}{|c|c|c|c|c|}
\hline & Location I & Location II & Location III & $\begin{array}{l}\text { Blank or } \\
\text { Spiked }\end{array}$ \\
\hline Time & A & A & $A B C$ & A \\
\hline Sample & 1 & 123 & 111 & 1 \\
\hline Aliquots Analyzed & $a b c$ & a a a & a a a & $a b c$ \\
\hline
\end{tabular}

In general preoperational data will not be generated by the same analytical or radiological counting equifment as will data from routine operations. It is, therefore, intended to use preoperational data to determine specific needs for routine analytical and counting apparatus. An example of using preoperational data to calculate the necessary minimum analytical detection limit follows:
Medium to be analyzed
- filter paper
Analytical recovery
- $70 \%$
Counting efficiency
- $25 \%$
Preoperational count rate -
Volume sampled
- 25 counts per minute
Time sampled
- $425 \mathrm{~m}^{3} / \mathrm{wk}$ (monthly composite)
- 40 hours 
BNWL -1723

$$
\begin{aligned}
& \text { MADL }=2 \sqrt{25}=10 \mathrm{cpm} \\
& 10 \frac{\text { count analyzed }}{\mathrm{min}} \times \frac{\text { dis }}{.25 \text { count }} \times \frac{\text { min } \mathrm{pCi}}{2.2 \text { dis }} \times \frac{\text { sampled }}{.7 \text { analyzed }}=26 \mathrm{pCi} \\
& \frac{26 \mathrm{pCi}}{1700 \mathrm{~m}^{3}}=.015 \frac{\mathrm{pCi}}{\mathrm{m}^{3}} \quad \text { (for comparisons see Appendix } \mathrm{C} \text { ) }
\end{aligned}
$$

\section{Data Records and Reports}

\section{a) Records}

The need for adequate and readily-audited environmental data records is not always obvious to operational staff with industrial background, especially where the data is not directly required for operational purposes and when the bulk of the data, as is frequently the case with environmental measurements, will be below detection levels or vary within narrow limits over long periods of time. There is a natural tendency in such cases to scan the incoming data, file it, and forget it. To insure that significant trends in environmental radiation levels are not overlooked by the 1icensee, it is necessary to establish an adequate records system beginning with the preoperational survey, including documentation of appropriate statistical and quality control procedures.

Tabulation of individual results by location over a time period of at least a year permits easy scanning and relation of new data to previous patterns. A complete set of such tabulations, maintained either manually or by computer printout, is the raw material with which the environmental evaluator works. Even more helpful is graphical presentation of at least key measurements. Maintenance of all records in the units to be used for reporting minimizes confusion and eases report preparation. Posting of results for the program already described would require little effort, perhaps an hour per month.

\section{(b) Data Evaluation}

As indicated in previous sections, trend evaluation is a primary usage of the environmental data. The preoperational survey will 
provide intial estimates of background levels with statistical confidence intervals for each contaminant-media combination. Operational experience may subsequently show certain measurements which are consistently higher than background, for which new confidence intervals should be calculated. In either case, confirmed measurements falling outside previously-determined confidence intervals should be investigated for possible changes in effluent release rates or in sampling and measurement procedures. In this way, long-term accumulations may be indicated which would require eventual action to reduce effluent release rates. It is especially important, with required detection levels and action guides based on background measurements, that attention be given to annual cycles and long-term changes in background levels determined by the preoperational survey program. Data from the remote locations, assumed to be unaffected by facility operation, must be reviewed routinely for any such evidence. Isotopic ratios will be found most useful in determining plant sources from other potential sources of changing environmental conditions.

A major problem facing the environmental evaluator is always the estimation of population dose. This is especially true with fuel fabrication plants, where the most significant exposures are apt to be those from airborne materials. Although particle size and chemical composition of the materials control the uptake from inhalation and the subsequent radiation dose to various organs of the body, these data are not readily and cheaply obtainable nor is there unequivocal guidance available to permit ready translation of measurements to dose for any but the highly skilled. Pending future authoritative guidance, it is assumed that the licensee may simply compare radionuclide air concentration data with Concentration Guides given in 10CFR20 as fractions of those limits and calculate corresponding individual organ doses. The more recent ICRP Handbooks $(25,29)$ provide methodology for calculating doses from estimated exposures, both single-event and chronic. Dose contributions to the critical organs from other significant pathways should, of course, be accounted for, estimates should be made for the 
Maximum Individual (or Critical Population Group) as well as some population average, and the contribution of regional fallout from atmospheric weapons testing and other nuclear facilities estimated and subtracted.

Comparisons of non-radioactive contaminant levels with appropriate federal, state, and possibly local water and ambient air quality standards are relatively straightforward. Generally, plant emissions should be sufficiently low that limiting criteria for environmental media will not be approached. This is not necessarily true in industrial areas, however, where preoperational concentrations may already approach or even exceed environmental quality standards, and some expansion of this part of the survelllance program may be necessary to provide reasonable proof that the licensed facility is not an offender.

Changes in background levels, in plant processes and effluent emissions, in environmental accumulations and especially in land usage and population distribution wi11, over a period of years, justify modifications in the initial surveillance program. Experience will indicate, and the licensee should be alert for, relationships between local environmental results which may reasonably permit some reduction of the program if properly documented. Annual review of the entire program in detail is advised to insure that such changes are made on a planned and justified basis.

\section{(c) Reports}

Reports of environmental program results may eventually be required. Such a requirement is likely to specify the following information: For each location and analysis, the maximum, minimum, annual average, standard deviation, and number of measurements for the year should be tabulated. Text material should include a description of the facility, local land usage and unique food or cultural practices, population distribution, estimates of composite maximum and population 
doses, and comparisons of these doses, with predicted values based on plant effluent, meteorological, and hydrological data. The report should also include discussion of any unusual environmental results, a summary of audit sample results, and a listing of any changes in the routine surveillance program.

Environmental data pertinent to any unusual releases, reportable under the provisions of 10CFR20 or other regulations, should be included as part of the report of the event. 
BNWL-1723

\section{BIBLIOGRAPHY}

1 Andelman, J.B., and T.C. Rozze11. "Plutonium in the Environment--Characteristics of Aqueous Plutonium," Advances in Chemistry, Series 93, Amer. Chem. Soc., Washington, D.C., 1970.

2 Basic Radiation Protection Criteria. National Council on Radiation Protection and Measurement, Report No. 39, 1971.

3 Chapman, W.H., et.al. Concentration Factors of Chemical Elements in Edible Aquatic Organisms, UCRL-50564, Univ. of Calif., Livermore, Calif., December 30, 1968.

4 Chu, N.Y. "Plutonium Determination in Soil by Leaching and Ion-Exchange Separation," Anal. Chem., 43:449-452, 1971.

5 Code of Federal Regulations, Title 40, Protection of Envirorment, "Standards of Performance for New Stationary Sources, "Part 60, Superintendent of Documents, GPO, Washington, D.C., 1972.

6 Code of Federal Regulations, Title 40, Protection of Environment, "National Primary and Secondary Ambient Air Quality Standards, "Part 50, Superintendent of Documents, GPO, Washington, D.C., 1972.

7 Code of Federal Regulations, Title 10, U.S. Atomic Energy Commission, "Standard for Protection Against Radiation", Part 20, Superintendent of Documents, GPO, Washington, D.C.,1971.

8 Code of Federal Regulations, Tit7e 10, U.S. Atomic Energy Commission, "Licensing of Production and Utilization Facilities, Part 50, App. I, Superintendent of Documents, GPO, Washington, D.C. 1971.

9 Community Air Quality Guides. "Inorganic Fluorides," American Industrial Hygiene Assoc., 1969.

10 Community Air Quality Guides. "Rational," American Industrial Hygiene Assoc., 1968.

11 Community Air Quality Guides. "Total Particulate Matter," American Industrial Hygiene Assoc., 1969.

12 Control Chart Method of Analyzing Data. American Standard Z1.2, 1958, Amer. Standards Assoc., 1958.

13 Currie, L.A. "Limits of Qualitative Detection and Quantitative Determination," Ana 1. Chem., 40:586-593, 1968.

14 Essig, T.H. and J.P. Corley. Criteria Used to Estimate Radiation Doses Received by Persons in the Vicinity of Hanford, BNWL-1019. Pacific Northwest Labs., Richland, Wash., Apri1, 1969. 
15 Federal Radiation Council. Background Material for the Development of Radiation Protection Standards, FRC Report No. 1, Superintendent of Documents, GP0, Washington, D.C., 1960.

16 Federal Water Quality Administration. Guidelines for State Water Quality Legislation,

17 Frant, M.S. and J.W. Ross, Jr. "Electrode for Sensing Fluoride Ion Activity in Solution," Science, 154:1553-1556, 1966.

18 Freke, A.M. "A Model for the Approximate Calculations of Safe Rates of Discharge of Radioactive Wastes into Marine Environments," Health Physics, 13:743-758, 1967.

19 Guide for Quality Control. American Standard 21.1-1958, Amer. Standards Assoc., 1958.

20 Guide to Sampling Airborne Radioactive Materials in Nuclear Facilities. ANSI N13.1-1969, Amer. Nat'1 Standards Inst., Inc., 1969.

21 Harley, J.H., (ed). Manual of Standard Procedures, D-04, NYO-4700, AEC Health \& Safety Lab.

22 Hartwe11, J.K. Detection Limits for Radioisotopic Counting Techniques, ARH-2537, U. S. Atomic Energy Commission, p. 16, 1972.

23 Healy, J.W. and J.J. Fuquay. "Wind Pickup of Radioactive Particles from the Ground," Proceedings of the 2nd International Conf. on Peaceful Uses of Atomic Energy, Geneva, 1958.

24 Hi11, A.C. "Air Quality Standards for Fluoride Vegetation Effects," J. Air Pollution Assoc., 19:331, 1968.

25 International Commission on Radiological Protection. The Assessment of Internal Contamination Resulting from Receivement or Prolonged Uptakes, ICRP Pub. 10A, Pergamon Press, Oxford, 1971.

26 International Commission on Radiological Protection. Report of Committee II on Permissible Dose for Internal Radiation, Pergamon Press, Oxford, 1959.

27 International Commission on Radiological Protection. Radiation Protection Recommendations as Amended (2) 1959 and Rev. 1962, ICRP Pub. 6, Pergamon Press, 0xford, 1964.

28 International Commission on Radiological Protection. Principles of Environmental Monitoring Related to the Handling of Radioactive Materials, ICRP Pub. 7, Pergamon Press, 0xford, 1966.

29 International Commission on Radiological Protection. Report of Committee IV on Evaluation of Radiation Doses to Body Tissues from Internal Contamination due to Occupational Exposure, ICRP Pub. 10, Pergamon Press, 0xford, 1968. 
30 Intersociety Committee. Methods of Air Sampling and Analysis, Amer. Public Health Services Assoc., Washington, D.C., pp. 246-265, 1972.

31 Intersociety Committee. Methods of Air Sampling and Analysis--Addendum, Amer. Public Health Services Assoc, Washington, D.C. (to be issued).

32 Johnston, J.W. An Index of Adequacy and Some 0ther Statistical Considerations for an Environmental Monitoring System, BNWL-B-250, Pacific Northwest Labs., Richland, Wash, 1973.

33 Joint WHO/FAO Committee. Methods of Radiochemical Analysis. FAO Atomic Energy Series No. 1, Food and Agriculture Organization of the United Nations, Rome, 1959.

34 Joint WHO/FAO Committee. Organization of Surveys for Radionuclides in Food and Agriculture, FAO Atomic Energy Series No. 4, Food and Agriculture Organization of the United Nations, Rome, 1962.

35 Krey, P.W., D. Bogen, and E. French. "Plutonium in Man and His Environment," Nature, 195:263, 1962.

36 Langham, W.H. "Plutonium Distribution as a Problem in Environmental Science," Proceedings of Environmental Plutonium Symposium, LA4756, 1971.

37 Laws of the United States Relating to Water Pollution Control and Environmental Quality. U.S. House of Representatives Committee on Public Works, Ju1y, 1970

38 McFarren, E.F., B.J. Moorman, and J.H. Parker. Water Fluoride, No. 3, Study No. 33, Analytical Reference Service, USDHEW, Environmental Control Admin., Cincinnati, Ohio, 1969.

39 Manual on Environmental Monitoring in Normal Operation. IAEA Safety Series No. 16, International Atomic Energy Agency, Vienna, 1966.

40 Manual on Environmental Monitoring in Emergency Situations. IAEA Safety Series No. 18, International Atomic Energy Agency, Vienna, 1966.

41 "Methods for Radiochemical Analysis." Report of a Scientific Meeting, World Health Organization, Geneva, 1966.

42 Mitche11, R.F. "Electrodeposition of Actinide Elements at Tracer Concentration," Anal. Chem., 32:326-28, 1960.

431972 Annual Book of ASTM Standards. Part 23, "Water, Atmospheric Analysis," Amer. Soc. for Testing and Materials, Philadelphia, Pa., 1972.

44 National Research Council. Fluorides, A Report, Committee on Biological Effects of Atmospheric Pollutants of the Division of Medical Sciences, Washington, D.C., 1971.

45 Noshkin, V.E. "Ecological Aspects of Plutonium Dissemination in Aquatic Environments," Health Physics, 22:537-549, 1972. 
BNWL -1723

46 0lafson, J.H. and K.H. Larson. Plutonium, its Biology and Environmental Persistence, USAEC Report, UCLA-501, Univ. of Calif., LOS Angeles, Dec., 1961.

47 Polikarpov, G.G. Radioecology of Aquatic Organisms, Reinhold Book Div., N.Y., 1966.

48 Price, K.R. A Critical Review of Biological Accumulation, Discrimination and Uptake of Radionuclides Important to Waste Management Practices, 1943-1971, BNWL-B-148, Pacific Northwest Labs., Richland, Wash., Dec., 1971.

49 Price, K.R. Uptake of $\mathrm{Np}, \mathrm{Pu}, \mathrm{Am}$, and $\mathrm{Cm}$ from Soil by Tumbleweed and Cheatgrass, BNWL-1688, Pacific Northwest Labs., Richland, Wash., Oct., 1972.

50 Procedures for Determination of Stable Elements and Radionuclides in Environmental Samples, PHS 999-RH-10, Public Health Service, Feb., 1965.

51 Public Health Service Drinking Water Standards. PHS-956, Rev. 1962, Superintendent of Documents, GPO, Mashington, D.C., 1aG?.

52 Quality Control of Radioactivity-Counting System. PHS-999-RH-15, Superintendent of Documents, GPO, Washington, D.C., 1965.

53 Radiation Protection in Nuclear Reactor Fuel Fabrication Plants. ANSI, N7.2-1963, Amer. Standards Assoc., Inc., N.Y., 1963.

54 "Routine Surveillance for Radionuclides in Air and Water." Report of a Technical Meeting, World Health Organization, Geneva, 1968.

55 Reinig, W.C. (ed.) "Environmental Surveillance in the Vicinity of Nuclear Facilities," Proceedings of a Symposium Sponsored by the Heal th Physics Society, Charles C. Thomas, Springfie1d, 111., 1970.

56 Sax, N.I. Dangerous Properties of Industrial Materials, Reinhold Book Corp. , 3rd. ed., 1968.

57 Setter, L.R. and G.I. Coats. "The Determination of Airborne Radioactivity," Am. Ind. Hyg. Assoc. J., 22:64, 1961.

58 Setter, L.R., G.R. Hagee, and C.P. Straub. Analysis of Radioactivity in Surface Waters: Practical Laboratory Methods, Bul. 227, p. 35, Amer. Soc. for Testing and Materials, Philadelphia, Pa., 1958.

59 Slade, D.H. (ed.) Meteorology and Atomic Energy, USAEC/Div. of Tech. Info., Washington, D.C., 1968.

60 Soldat, J.K. Private communication.

61 State of Washington Department of Ecology. "Summary of Ambient Air Quality Standards as of Aug. 1, 1970,"WAC 18-48, Washington State Air Pollution Control Board Regulations, March 12, 1971. 
62 Stein, John L., et. al. "Evaluation of the Sampling Frequency of the Pasteurized Milk Network," Rad. Health Data and Reports, V.12, No. 9, Sept., 1971 .

63 Subcommittee on Environmental Surveillance, Routine Surveillance of Radioactivity Around Nuclear Facilities. PHS 999-RH-23, DHEW, Div. of Radiological Health, Washington, D.C., Dec., 1966.

64 Terril1, J.G., Jr., C.L. Weaver, E.D. Harward, D.R. Smith. "Environmental Surveillance of Nuclear Facilities," Nuclear Safety, V. 9, No. 2, MarchApri1, 1968.

65 Thompson, R.C. and W.J. Bair, (eds.) "The Biological Implications of the Transuranium Elements," Proceedings of the 11 th Biology Symposium held at Richland, Washington, 27-29 Sept., 1971, Health Physics J., V. 22, No. 6, June, 1972.

66 Threshold Limit Values for 1970. Amer. Conf. of Governmental Industrial. Hygienists, Cincinnati, Ohio, 1971.

67 Turner, D.B. Workbook of Atmospheric Dispersion Estimates, PHS 999-AP-26, DHEW, National Center for Air Pollution Control, Cincinnati, Ohio, 1967.

68 Weaver, C.L. Environmental Radiation Surveillance and Monitoring, Div. of Surveillance and Inspection, Office of Rad. Prog., EPA, Rockville, Md., JuTy, 1971.

69 Wick, 0.J. (ed.) Plutonium Handbook: A Guide to the Technology, V. I and II, Gordon and Breach, Science Pub7., N.Y., 1967.

70 Wong, K.M. "Radiochemical Determination of Plutonium in Seawater, Sediments and Marine Organisms," Ana1. Chim. Acta, 56:355, 1971. 


\section{APPENDIX A}

APPLICABLE FEDERAL REGULATIONS ON ENVIRONMENTAL RADIOACTIVITY

10 CFR 20

20.1 Purpose

(c) In accordance with recommendations of the Federal Radiation Council, approved by the President, persons engaged in activities under licenses issued by the Atomic Energy Commission pursuant to the Atomic Energy Act of 1954, as amended, should, in addition to complying with the requirements set forth in this part, make every reasonable effort to maintain radiation exposures, and releases of radioactive materials in effluents to unrestricted areas, as far below the limits specified in this part as practicable. The term "as far below the limits specified in this part as practicable" means as low as is practicably achievable taking into account the state of technology, and the economics of improvements in relation to benefits to the public health and safety and in relation to the utilization of atomic energy in the public interest.

10 CFR 20

20.105 Permissible Levels of Radiation in Unrestricted Areas

(a) There may be included in any application for a license or for amendment of a license proposed limits upon levels of radiation in unrestricted areas resulting from the applicant's possession or use of radioactive material and other sources of radiation. Such applications should include information as to anticipated average radiation levels and anticipated occupancy times for each unrestricted area involved. The Commission will approve the proposed limits if the applicant demonstrates that the proposed limits are not likely to cause any individual to receive a dose to the whole body in any period of one calendar year in excess of 0.5 rem.

(b) Except as authorized by the Commission pursuant to paragraph (a) of this section, no licensee shal1 possess, use of transfer licensed 
APPENDIX A (Continued)

material in such a manner as to create in any unrestricted area from radioactive material and other sources of radiation in his possession:

(1) Radiation levels which, if an individual were continuously present in the area, could result in his receiving a dose in excess of two millirems in any one hour, or

(2) Radiation levels which, if an individual were continuously present in the area, could result in his receiving a dose in excess of $100 \mathrm{millirems}$ in any seven consecutive days.

20.106 Radioactivity in Effluents to Unrestricted Areas

(a) A 1 icensee shall not possess, use, or transfer licensed material so as to release to an unrestricted area radioactive material in concentrations which exceed the limits specified in Appendix B, Table I I of this part, except as authorized pursuant to 20.302 or paragraph (b) of this section. For purposes of this section concentrations may be averaged over a period not greater than one year.

(b) An application for a license or amendment may include proposed limits higher than those specified in paragraph (a) of this section. The Commission will approve the proposed limits if the applicant demonstrates:

(1) That the applicant has made a reasonable effort to minimize the radioactivity contained in effluents to unrestricted areas; and,

(2) That it is not likely that radisactive material discharged in the effluent would result in the exposure of an individual to concentration of radioactive material in air or water exceeding the limits specified in Appendix B, Table II of this part.

(c) An application for higher limits pursuant to paragraph (b) of this section shall include information demonstrating that the applicant has made a reasonable effort to minimize the radioactivity discharged in effluents to unrestricted areas, and shall include, as pertinent:

(1) Information as to flow rates, total volume of effluent, peak concentration of each radionuclide in the effluent, and concentration of each radionuclide in the effluent averaged over a period of one year at the point where the effluent leaves a stack, tube, pipe, or similar conduit; 
APPENDIX A (continued)

(2) A description of the properties of the effluents, including:

(i) chemical composition

(ii) Physical characteristics, including suspended solids content in luquid effluents, and nature of gas or aerosol for air effluents;

(iii) the hydrogen ion concentrations (pH) of liquid effluents; and

(iv) The size range of particulates in effluents released into air.

(3) A description of the anticipated human occupancy in the unrestricted area where the highest concentration of radioactive material from the effluent is expected, and, in the case of a river or stream, a description of water uses downstream from the point of release of the effluent.

(4) Information as to the highest concentration of each radionuclide in an unrestricted area, including anticipated concentrations averaged over a period of one year:

(i) In air at any point of human occupancy, or;

(ii) In water at points of use downstream from the point of release of the effluent.

(5) The background concentration of radionuclides in the receiving river or stream prior to the release of liquid effluent.

(6) A description of the environmental monitoring equipment, including sensitivity of the system, and procedures and calculations to determine concentrations of radionuclides in the unrestricted area and possible reconcentrations of radionuclides.

(7) A description of the waste treatment facilities and procedures used to reduce the concentration of radionuclides in effluents prior to their release.

(d) For the purposes of this section the concentration limits in Appendix B, Table II of this part shall apply at the boundary of the restricted area. The concentration of radioactive material discharged 


\section{APPENDIX A (Continued)}

through a stack, pipe, or similar conduit may be determined with respect to the point where the material leaves the conduit. If the conduit discharges within the restricted area, the concentration at the boundary may be determined by applying appropriate factors for dilution, dispersion, or decay between the point of discharge and the boundary.

(e) In addition to limiting concentration in effluent streams, the Commission may limit quartities of radioactive material released in air or water during a specified period of time if it appears that the daily intake of radioactaive material from air, water, or food by a suitable sample of an exposed population group, averaged over a period not exceeding one year, would otherwise exceed the daily intake resulting from continuous exposure to air or water contaning $1 / 3$ the concentration of radioactive materials specified in Appendix $B$, Table II, of this part.

(f) The provisions of this section do not apply to disposal of radioactive material into sanitary sewerage systems, which is governed by 20.303.

20.303 Disposal by Release into Sanitary Sewerage Systems

No 1 icensee shall discharge licensed material into a sanitary sewerage system unless:

(a) It is readily soluble or dispersible in water; and,

(b) The quantity of any licensed or other radioactive material released into the system by the 7 icensee in any one day does not exceed the larger of sub-paragraphs (1) or (2) of this paragraph:

(1) The quantity which, if diluted by the average daily quantity of sewage released into the sewer by the 1 icensee, will result in an average concentration equal to the limits specified in Appendix $B$, Table I, Column 2 of this part; or,

(2) Ten times the quantity of such material specified in Appendix $C$ of this part; and,

(c) The quantity of any licensed or other radioactive material released in any one month, if diluted by the average monthly quantity of water 
APPENDIX A (Continued)

released by the licensee, will not result in an average concentration exceeding the limits specified in Appendix B, Table I, Column 2 of this part; and,

(d) The gross quantity of licensed and other radioactive material released into the sewerage system by the licensee does not exceed one curie per day. 
APPENDIX B

NONRADIOLOGICAL ENVIRONMENTAL STANDARDS

TABLE B-1. Fresh Surface Waters Receiving Water
Quality Criteria for Liquid Effluents

Constituent or

Characteristic

$\frac{\text { Physical }}{\text { Color }}$
Teniperature
Turbidity

Biological

Coliform Organisms

Biochemical Oxygen Demand

Inorganic Chemicals

Ammonia

Arsenic

Barium

Boron

Cadmium

Chloride

Chromium, hexavalent

Copper

Cyanides

Dissolved Oxygen

Fluoride

Iron (filterable)

Lead

Manganese (filterable)

Nitrates plus nitrites

$\mathrm{pH}$ range

Selenium

Silver

Sulfate

Total Dissolved Solids

Uranyl ion

Zinc

$\frac{\text { Organic Chemicals }}{\text { Oil and grease }}$

\begin{tabular}{c} 
Permissible \\
Criteria \\
\hline
\end{tabular}

75

$65^{\circ} \mathrm{F}(\mathrm{b})$

$20 \mathrm{ppm}$

$100 / 100 \mathrm{ml}$

$10 \mathrm{ppm}$

$(\mathrm{mg} / 1)$

0.5 (as N)

0.05

1.0

1.0

0.01

250

0.05

1.0

0.2

$\geq 4$

$0.7-1.2$

0.3

0.05

0.05

10 (as N)

$6.5-8.6$

0.1

0.05

250

500

5.0

5.0

Virtually absent
Most Restrictive Media

Public Water Supply (PWS) Recreation ( $R$ )

$\mathrm{R}$

$R$

$\mathrm{R}$

Farmstead (F) \& PWS

$F$ \& PWS

PWS

$F$ \& PWS

PWS

$\mathrm{F}$

$F$ \& PWS

$\mathrm{F}$

$\mathrm{F}$

$F$ \& PWS

$F$ \& PWS

$F$ \& PWS

PWS

$\mathrm{R}$

$F$ \& PWS

$F$ \& PWS

PWS

F \& PWS

PWS

$F$ \& PWS

a. Taken from "Water Quality Criteria," Federal Water Quality Administration (1968)

b. Other specific temperature criteria may apply on individual streams. 


\section{TABLE B-2. Federal Ambient Air Quality Criteria}

"Allowable" Concentration

\section{Carbon Monoxide (primary and secondary)}

Suspended Particulates (primary)

(secondary)

Photochemical

oxidants

(primary and

secondary)

Hydrocarbons (primary and secondary) measured and corrected for methane

Nitrogen Dioxide (primary and secondary)

Sulfur Oxides (primary) measured as sulfur dioxide

(secondary) a. 10 milligrams per cubic meter (9 ppm)-maximum 8-hour concentration not to be exceeded more than once per year.

b. 40 milligrams per cubic meter (35 ppm)-maximum 1-hour concentration not to be exceeded more than once per year.

a. 75 micrograms per cubic meter--annual geometric mean.

b. 260 micrograms per cubic meter--maximum 24-hour concentration not to be exceeded more than once per year.

a. 60 micrograms per cubic meter--annual geometric mean, as a gulde to be used in assessing implementation plans to achieve the 24-hour standard.

b. 150 micrograms per cublc meter--maximum 24-hour concentration not to be exceeded more than once per year.

160 micrograms per cublc meter $(0.08$ ppm)-maximum 1-hour concentration not to be exceeded more than once per year.

160 micrograms per cubic meter $(0.24 \mathrm{ppm})--$ maximum 3-hour concentration ( 6 to $9 \mathrm{a} . \mathrm{m}$.) not to be exceeded more than once per year.

100 micrograms per cublc meter $(0.05$ ppm)-annual arithmetic mean.

a. 80 micrograms per cubtc meter $(0.03$ ppm)-annual arithmetic mean.

b. 365 micrograms per cublc meter $(0.14 \mathrm{ppm})-$-maximum 24-hour concentration not to be exceeded more than once per year

a. 60 micrograms per cubic meter $(0.02$ ppm)-annual arithmetic mean. 
TABLE B-2 (Continued)

b. 260 micrograms per cubic meter $(0.1 \mathrm{ppm})--$ maximum 24-hour concentration not to be exceeded more than once per year, as a guide to be used in assessing implementation plans to achieve the annual standard.

c. 1,300 micrograms per cubic meter $(0.5 \mathrm{ppm})--$ maximum 3-hour concentration not to be exceeded more than once per year. 
TABLE B-3. Washington State Ambient Air Quality Criteria

"A1lowable" Concentration

$\frac{\text { Carbon Monoxide }}{\text { (primary and }}$
secondary)
$\frac{\text { Suspended Particulates }}{(\text { primary) }}$

Particle Fallout

Photochemical

oxidants

(primary and

secondary)

Hydrocarbons

(non-methane)

$\frac{\text { Nitrogen Dioxide }}{\text { (primary and }}$

Sulfur Oxides

(as $\mathrm{SO}_{2}$ ) a. $\overline{10}$ milligrams per cubic meter (9 ppm)-- 8-hour average concentrations not to be exceeded more than once per year.

b. 40 milligrams per cubic meter ( $35 \mathrm{ppm})--$ 1-hour average concentration not to be exceeded more than once per year

a. 60 micrograms per cubic meter--annua 1 geometric mean

b. 150 micrograms per cubic meter--maximum 24-hour average concentration not to be exceeded more than once per year.

Sha11 not exceed 2.5 grams per square meter per month.

Shall not exceed hourly average concentration of 160 micrograms per cubic meter. (0.08 ppm) more than once from Apri1 1 through October 31 during hours of 10:00 a.m. to 4:00 p.m.

Sha11 not exceed a 3-hour average concentration of 160 micrograms per cubic meter $(0.24 \mathrm{ppm})$-more than once from Apri1 1 through October 31 during the hours of 6:00 a.m. to 9:00 a.m.

Sha11 not exceed 100 micrograms per cubic meter (0.05 ppm)--annual arithmetic mean.

Shall not exceed:

a. $\quad 0.4 \mathrm{ppm}$-hourly average not to be exceeded more than once per year.

b. $0.25 \mathrm{ppm}$ - hourly average not be exceeded more thantwice in any 7-day period.

c. 0.1 ppm--daily average not to be exceeded more than once per year.

d. 0.02 ppm--annual arithmetic mean. 
TABLE B-3 (Continued)

Fluoride

a. Forage

a. $40 \mathrm{ppm}$ by wt. average for any 12 consecutive months.

b. $60 \mathrm{ppm}$ each month for more than 2 consecutive months.

c. $80 \mathrm{ppm}$ more than once in any 2 consecutive months.

d. Cured forage, $40 \mathrm{ppm}$.

b. Ambient Air a. 3.7 micrograms per cubic meter average for any 12 consecutive hours.

b. 2.9 micrograms per cubic meter average for any 24 consecutive hours.

c. 1.7 micrograms per cubic meter average for any 17 consecutive days.

d. 0.84 micrograms per cubic meter average for any 30 consecutive days.

e. 0.5 micrograms per cubic meter average for the period March 1 - October 31 of any one year. 


\section{APPENDIX C}

\section{Minimum Analytical Detection Limits}

for Environmental Surveillance

The analytical detection limits listed below are currently achievable with modern equipment, good laboratory practices, and sufficiently large samples and counting times. In keeping with the discussion in Sect. 3 and Appendix D, this analytical detection limit (ADL) is defined as $2 \times \sqrt{\text { Background }}$ for blank samples using identical techniques. The implication of this definition is that the measured value of a sample with a true concentration at the ADL will be within $\pm 100 \%$ of this value about $95 \%$ of the time. To better define adequacy of laboratory performance, a permissible standard deviation at some multiple of the ADL should also be specified, e.g. $\pm 30 \%$ at 10 times ADL. No commonly accepted value for plutonium analyses exists at present, although some reported data indicates better precision than the example given for plutonium in soil.

\section{TABLE C-1. Proposed Minimum Analytical \\ Detection Limits}

\begin{tabular}{|c|c|c|}
\hline Medium & Nuclide $^{(a)}$ & Proposed ADL \\
\hline Air & $\begin{array}{l}\text { Uranium } \\
\text { Plutonium }\end{array}$ & $\begin{array}{l}0.005 \mathrm{pCi} / \mathrm{m}_{3}^{3} \\
0.005 \mathrm{pCi} / \mathrm{m}^{3}\end{array}$ \\
\hline Water & $\begin{array}{l}\text { Uranium } \\
\text { Plutonium }\end{array}$ & $\begin{array}{l}4 \mathrm{pCi} / \mathrm{l} \\
0.01 \mathrm{pCi} / \mathrm{l}\end{array}$ \\
\hline $\begin{array}{l}\text { Foodstuffs } \\
\text { and } \\
\text { Vegetation }\end{array}$ & $\begin{array}{l}\text { Uranium } \\
\text { Plutonium }\end{array}$ & $\begin{array}{l}0.02 \mathrm{pCi} / \mathrm{g} \\
0.005 \mathrm{pCi} / \mathrm{g}\end{array}$ \\
\hline Soil & $\begin{array}{l}\text { Uranium } \\
\text { Plutonium }\end{array}$ & $\begin{array}{l}0.02 \mathrm{pCi} / \mathrm{g} \\
0.005 \mathrm{pCi} / \mathrm{g}\end{array}$ \\
\hline
\end{tabular}

(a) Values for plutonium may De used for other alpna-emitting transuranic nuclides.

*Assuming the isotopic ratio of natural uranium as defined in TOCFR20. other enrichments must be treated according to their isotopic ratios. 


\section{APPENDIX D}

Some Statistical Considerations and An Index of

Adequacy for an Environmental Surveillance System

\section{A. INTRODUCTION}

This appendix defines a statistical model which expresses the values observed from analysis of a nuclide-media sample in terms of the "effects" which could cause the observed values to deviate from the true (but unknown) average annual level. An index of the "adequacy" of the system for monitoring a nuclide-media combination is developed in terms of the model and the statistical risks to both the facility operator and the population to be protected (or at least reassured) by the monitoring system. 
BNWL -1723

\section{B. MODEL DEFINITION}

In order to provide a firm basis for the discussion to follow, a statistical model of the measurements obtained from the analysis of a sample aliquot for the nuclide concentration in a specified media will be introduced. The model is:

$$
y_{i j k \ell}=\mu+\lambda_{i}+\tau_{j(i)}+(\lambda \tau)_{i j}+\beta_{i j}+n_{i j k}+\delta_{\varepsilon}+\varepsilon_{i j k \ell}
$$

Where

$y_{i j k \ell}$ is the measurement obtained from the analysis of the $e^{\text {th }}$ aliquot from sample $k$ taken at time $j$ from location $i$.

$\mu \quad$ is the annual mean concentration level of the nuclide in the media of interest for the geographic area under consideration.

$\lambda_{i} \quad$ is the differential effect due to location $i ; i=1, \ldots$, I; I is the number of sampling locations.

$\tau_{j(i)}$ is the differential effect due to time $j$ at location $i$; $\mathrm{j}=1, \ldots . \mathrm{J} ; \mathrm{J}$ is the number of time periods over the year represented by an analyzed sample.

$(\lambda \tau)_{i j}$ is the differential effect, over and above $\lambda_{i}$ and $\tau_{j}$, due to the interaction of time $j$ and place $i$.

$\beta_{i j}$ is the bias (consistent inaccuracy in measuring what is actually in the environment) due to the sampling technique used. It may be zero, a fixed quantity over time and place, or a function of $\lambda_{i}$ and/or $\tau_{j}$.

$n_{i j k}$ is the random effect due to replicate sample $k$ taken at location $i$ and time $j ; k=1, \ldots ., k$; $k$ is the number of replicates. In practice, $k$ usually is 1 , making it impossible to estimate the variance of $\eta_{i j k}$.

$\delta_{\varepsilon}$ is the bias due to the sample handling, analytical and calculational methods used.

$\varepsilon_{i j k \ell}$ is the random effect due to replicate analysis $\ell$ on sample $k$ from location $i$ for time $j ; l=1, . . ., L$. 
It is assumed that:
(1) $\varepsilon_{i j k \ell}$ are $\operatorname{NID}\left(0, \sigma_{\varepsilon}^{2}\right)(a)$
(2) $\eta_{i j k}$ are $\operatorname{NID}\left(0, \sigma_{\eta}^{2}\right)$
(3) $\lambda_{i}$ are $\operatorname{NID}\left(0, \sigma_{\lambda}^{2}\right)$
(4) $\tau_{j(i)}$ are $\operatorname{ND}\left(0, \sigma_{\tau_{i}}^{2}\right)$
(5) $(\lambda \tau)_{i j}$ are $\operatorname{NID}\left(0, \sigma_{\lambda \tau i}^{2}\right)$
(6) $\beta_{i j}$ are fixed quantities estimated independently of the operational data. (Not to be confused with existing environmental background nor base-line data). They are based on the sampling scheme used.
(7) $\delta_{\varepsilon}$ are fixed quantities, estimated independently of the sampling scheme used, reflecting the biases in the measurement system.

The reader should avoid any tendency to view the model as analogous to an I $\times \mathrm{J}$ factorial "experiment". The ( $i$ ) subscript on the $\tau_{j}$ is intended to indicate that this model views the data as generated by repeated measurements over time at each location.

None of the quantities represented by the greek letters are known with certainty at any time before or after the analysis. The observed measurements, $y_{i j k \ell}$, are the basis for providing estimates of the unknown

(a) The expression $\operatorname{NID}\left(\mu, \sigma^{2}\right)$ means that the random variable of which it is predicted follows the normal (Gaussian) probability distribution with the mean equal to $\mu$ and variance equal to $\sigma^{2}$ and that the covariance between any pair of realizations of the random variable is zero; i.e., the variables are independent. Statistical treatment of data from the log-normally distributed data frequently encountered in studying environmental radionuclide levels can be the same as for normally distributed data, if the data are transformed by taking their logarithm. 
parameters (greek letters) in the model. By making assumptions regarding the functional form of the statistical (probabilistic) distribution of the random effects $\left(\eta_{i j k}\right.$ and $\left.\varepsilon_{i j k \ell}\right)$ it is possible to make statements about the degree of conffdence that can be placed in the estimates of the other differential effects and the overall mean. Usually biases must be determined independently of the data collected for environmental surveillance.

In order to clarify the meaning and applicability of the model let us consider the current practice for monitoring the concentration of radioactive beta particles in the air of the Hanford environs. Table 2, pp. 40-43 of BNWL-1683 ADD provides data from 17 locations and 51 time periods during 1971. The data are unusual in that only 1 of the total 867 data points was less than the Analytical Limit (AL) of $0.02 \times 10^{-12}$ $\mu \mathrm{Ci} / \mathrm{m} \ell\left(=.02 \mathrm{pCi} / \mathrm{m}^{3}\right)$, "invalid data" resulted from the analysis of the sample for 18 data points, and no beta activity analysis was reported for four samples. This left 844 samples with positive results reported.

Thus, for these data there are $I=17$ locations and $\mathrm{J}=51$ time periods at which samples were planned for analysis. Twenty-three of the planned observations can be considered as missing. The universe sampled is presumably the "Air of the Hanford Environs". Explicit information on the biases and random errors is not available in the reported data. The available data could provide estimates of the following parameters: $\mu, \lambda_{i}, \tau_{j(i)},(\lambda \tau)_{i j}, \sigma_{\lambda}^{2}, \sigma_{\tau_{i}}^{2}, \sigma_{\lambda \tau_{j}}^{2}$. But the estimates of the variances will be inflated since they include the variability due to the random sampling and measurement errors, and the estimates of effects will be inaccurate since they do not include corrections for sampling and measurement biases. The estimates of bias will also contribute variability to the total measurement process according to the following formula:

$$
V(X+Y)=V(X)+V(Y)+2 \operatorname{cov}(X, Y) \text {, }
$$

where $X$ is the observed value, $Y$ is the correction for bias, $V$ means variance and COV means covariance of the parenthesized random variables. 
BNWL -1723

\section{DATA TO BE COLLECTED}

The data recommended for collection in the program outlined by Table 2 of this document generally provide estimates of the mean annual concentration level in the media sampled. In some cases estimates of maximum inventory levels are obtained. The data can also be used for making locationto-location (particularly site affected vs. background) and time-to-time comparisons for determining the significance of trends.

The extent of the basic statistics available for analysis, if the recommended procedures are followed, is indicated in Table A-1. This table summarizes the data collected on each nuclide-media combination for each sampling location. In general, the year may be divided into $\mathrm{J}$ time periods, each period represented by a sample (continuous, composited or single) of material to be analyzed. In Table A-1, these individual time periods are classified into two "Sections" on the basis of two AL's used during the year. The first section has $J_{1}$ periods and the second $J_{2}$ for the total of $\mathrm{J}_{1}+\mathrm{J}_{2}=\mathrm{J}$. Each individual time period has three statistics associated with it: the detection level, $\mathrm{DL}_{j}$, the observed average concentration, $c_{j}$, and the observed standard deviation, $s_{j}$. Each section of the year and the annual summary also have statistics appropriate for the summary level. The $C_{j}$ are the averages of the observations, $J_{i j k 1}$, available for a time by location data point.

The adequacy of the monitoring system for each nuclide-media combination can only be evaluated from a clear understanding of how each entry in Table 1 is to be arrived at.

All the statistics listed should be filled in. The identification section at the top of the table is self-explanatory. Time periods should be numbered sequentially and the date of sample collection given under the column headed "Time." If composited samples are used for the media, the date when the last sample was taken should be given followed by the number of composited samples in parentheses. The second column, headed "Detection Leve1, DL," should be the average $D L$ over the $L_{j}$ runs for the analysis of the sample representing time $j$. The third column gives the 
The variance of the measurement errors, $\sigma_{\varepsilon}^{2}$, is estimatable through replicate analyses on separate aliquots from the same sample. The variance of the sampling errors, $\sigma_{n}^{2}$ is estimatable through replication of the sampling apparatus at location-time points (e.g., duplicate filters in close juxta-position). The bias in the measurement system, $\delta_{\varepsilon}$, can be determined from analyzing blanks and pseudosamples spiked to a quantity of activity which is known with high accuracy and precision. Another factor contributing to $\delta_{\varepsilon}$ is the calculational procedure used to convert counting spectra to intensity or absorption units (curies, rads). These conversion factors may have a degree of uncertainty associated with them which induce a bias in the end product of the calculation. The bias due to sampling, $\beta_{i j}$, is the most difficult to estimate. One approach to this problem would be to use more precise and accurate sampling and analytical techniques to sample the same environment in the same design that defines the operational procedures to be used, along with the operational procedures. Differences in the obtained results can be used as estimates of bias, but still beg the question that the more precise method more accurately measures what is really "out there". Some measurable biases due to sampling are derivable from: a) the known efficiency of filters, b) the flow rates through filters, c) the dept of soil samples and d) studies of dispersion in river water.

Current practice provides little insight into the level of sampling bias since most surveillance to date has been concerned with trends at sampling points, not with environmental levels. (Except for the international monitoring of fallout from atomic bomb testing.) Some indication of the level of sampling bias might be obtained by using "percent recovery". techniques in conjunction with monitoring of facility releases. 
Table A-1 Statistics Expected To Be Available From Monitoring A LocationNuclide-Media Combination Within A Stratum

Media

Nucl ide

From

Mo/Day/Yr

Stratum

Location

To

Analytical Method

Mo/Day/Yr

Concentration Unit

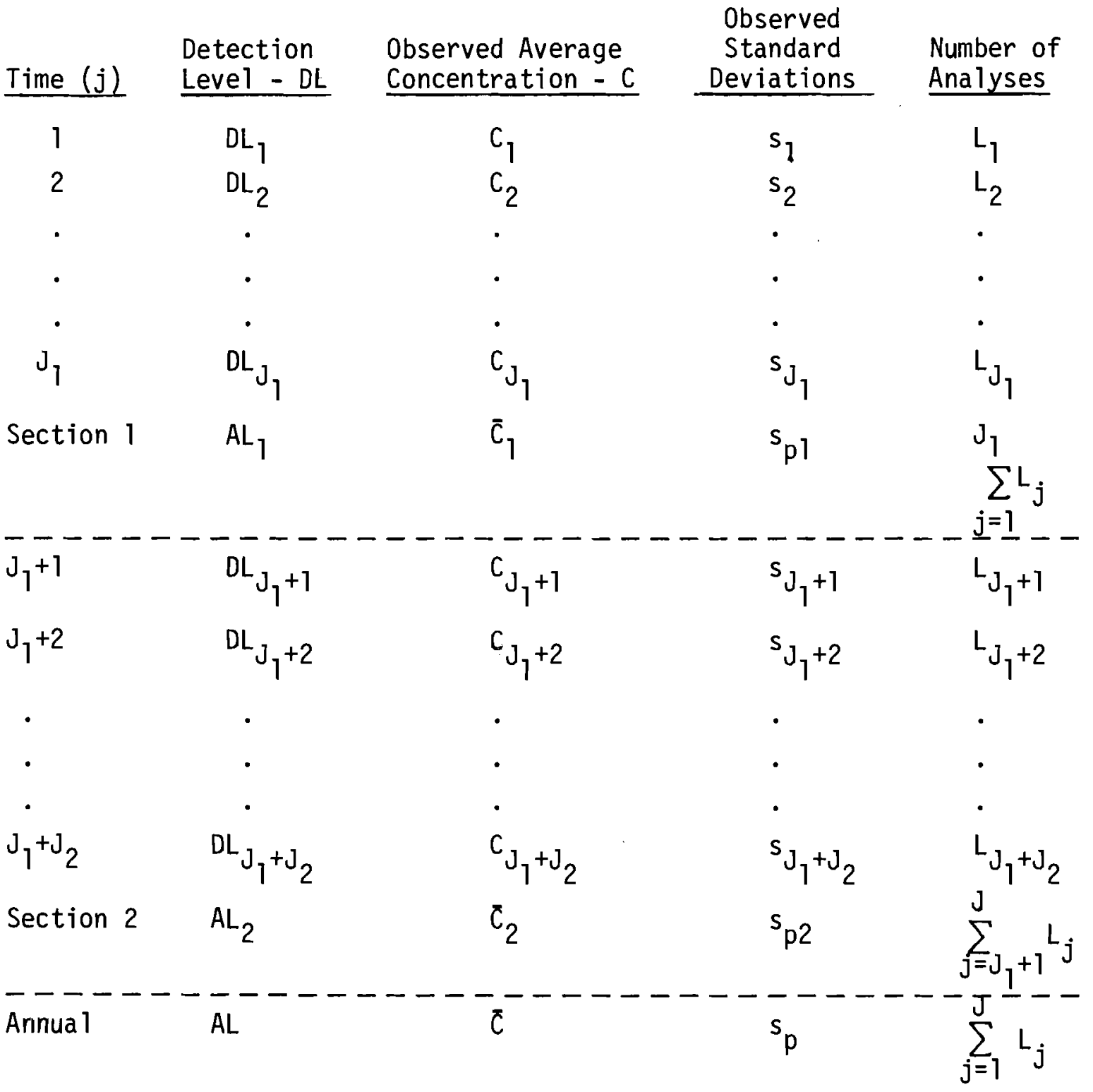


observed average concentration level. This level is the average of the observed results of the analytical runs on the sample representing time $j$. It is important to include values below the DL even if the calculations result in negative values. Unless negative values are included, the variance of the measurement errors will be estimated as less than it truly is. The fourth column gives the observed standard deviation of the replicate runs on the sample for time $j$. This quantity can be calculated only if $L_{j}$, the number of runs entered in the last column, is at least 2.

Given the data of Table A-l and the results of analytical quality control studies, the total variability of the sampling and measurement process can be estimated through analys is of variance techniques which eliminate the variability due to true fluctuations from time-to-time and place-to-place in the environment. In terms of the statistical model, the total variability is:

$$
\sigma_{T}^{2}=k_{1} \sigma_{\varepsilon}^{2}+k_{2} \sigma_{\eta}^{2}+k_{3} \sigma_{B}^{2}+k_{4} \sigma_{\delta}^{2}
$$

where the $k$ 's are constants depending on the numbers of samples analyzed, and $\sigma_{\beta}{ }^{2}$ and $\sigma_{\delta}{ }^{2}$ are the variances associated with the estimates of bias $\beta_{i j}$ and $\delta_{\varepsilon}$. This total variability plays an important role in the definition of the index of adequacy. 


\section{INDEX OF ADEQUACY}

Problem: Devise criteria for a surveillance system that gives $100(1-\alpha) \%$ confidence that a condition in which the population sampled contains at least the activity level specified by a concentration Guide, CG, will be detected $100(1-\beta) \%$ of the time in a timely manner.

This problem can be couched in terms of testing the hypothesis

$$
H_{0}: E L \leq C G
$$

against

$$
H_{A}: E L>C G
$$

where $\mathrm{EL}$ is the true Environmental Level.

Two types of decision errors can be made

\begin{tabular}{lll} 
& \multicolumn{2}{l}{ ENVIRONMENTAL STATUS } \\
\cline { 2 - 3 } DECISION & NL $\leq C G$ & EL $>C G$ \\
\hline$E L \leq C G$ & No Error & Type II $(\beta)$ \\
$E L>C G$ & Type I $(\alpha)$ & No Error
\end{tabular}

The statistical problem is to devise a sampling scheme which can provide the required latitude for the facility operator $(\alpha)$ with reasonable protection $(1-\beta)$ to the population given the sampling and measurement uncertainties and biases in the current state of the art. In addition to the statistical aspects the system should be easy and efficient in operation and not add substantially $(<1 \%$ ?) to the cost of facility operation.

The nul1 hypothesis, $\mathrm{H}_{0}$, states that the true situation is that the environmental level (EL) is not greater than the concentration guide $(C G)$. Given a value, $\bar{y}_{i j}$, from the analys is of the sample collected at time $j$ and location $i$ we allow a $100 \alpha \%$ chance of saying $E L>C G$ when in fact $E L \leq C G$ and a $100 \%$ chance of saying $E L \leq C G$ when in fact $E L>C G$. 
By assuming that long experience with the sampling method and analytical procedures has provided a precise estimate of $\sigma_{T}^{2}$, where $\sigma_{T}^{2}$ is the total variability due to sampling and measurement errors, we can devise a decision rule based on the normal distribution. This is: Reject $H_{0}: E L \leq C G$ whenever

$$
\left(\bar{y}_{i j} .-C G\right) / \sigma_{T}>z(1-\alpha)
$$

or whenever

$$
\bar{y}_{i j .}>C G+z_{(1-\alpha)} \sigma_{T}
$$

where $Z_{(1-\alpha)}$ is the $100(1-\alpha)$ percentile of the standard normal distribution.

The power function of this test is calculated under the assumption that the alternative hypothesis holds true and the alternative hypothesis is composite, in the sense that it specifies only that $\mathrm{CG}<\mathrm{EL}<\infty$. The power function then is

$$
\begin{aligned}
1-\beta & =p\left(\text { rejecting } H_{0} / H_{A} \text { is true }\right) \\
& =p\left(\frac{E L_{A}-C G}{\sigma_{T}}>Z_{(1-\alpha)}\right) \\
& =p\left(\frac{\left(C G+k_{A} \sigma_{T}\right)-C G}{\sigma_{T}}>Z(1-\alpha)\right) . \\
& =p\left(k_{A}>Z(1-\alpha)\right) \\
& =\int_{Z}^{\infty} n(1-\alpha) \\
& =\int^{\infty}\left(Z(1-\alpha)^{\left.-k_{A}\right)} n(0,1) d z\right.
\end{aligned}
$$


where, for a specified alternative and standard deviation, $\mathrm{EL}_{\mathrm{A}}$ and $\sigma_{T}$, $k_{A}$ is the solution to $E L_{A}=C G+k_{A} \sigma_{T}$

and

$$
\begin{aligned}
& \eta\left(\mu, \sigma^{2}\right) \text { is the normal frequency function with mean } \mu \text { and } \\
& \text { variance } \sigma^{2} \text {. }
\end{aligned}
$$

It is important to note that the last integral above depends only on the significance percentile, $Z_{(1-\alpha)}$, and the distance in standard deviation units of $E L_{A}$ from CG. Thus, the power of the test procedure can be calculated independently of the actual $\mathrm{CG}, \mathrm{EL}_{\mathrm{A}}$ and $\sigma_{T}$ for any specified significance (a) level from tables of the cumulative standard normal distribution. Further, given desired $\alpha$ and $\beta$ levels the value of $k_{A}$ which satisifies

$$
P\left(k_{A}>Z_{\alpha}\right)=1-B
$$

can be found from a table of the cumulative standard normal distribution as follows:

a. Find $\beta=\int_{-\infty}^{Z} n(0,1) d z$ in the table, e.g., $\beta=.005$.

b. $\operatorname{Read} Z_{\beta}$, e.g., for $\beta=.005, Z_{\beta}=-2.576$

c. Find $Z_{(1-\alpha)}$ in the table, e.g., for $\alpha=.05, Z_{(1-\alpha)}=1.645$

d. Then $z_{(1-\alpha)}-z_{B}=k_{A}$, e.g., $k_{A}=1.645-(-2.576)=4.221$

Table A-2 provides some $k_{A}$ 's for common values of $\alpha$ and $B$. This table can provide some insight into the danger of not considering the degree of protection afforded the population in designing surveillance systems. It should be pointed out that this "normal theory" case represents the upper limit of the power obtainable through use of the t-test, the procedure usually used. That is, the protection (1-B) levels discussed here are better than those obtained in practice for the nominal $\alpha$-level procedures customarily used.

If the operator sets his risk at $\alpha=0.05$, he only assures the population that he will detect an EL of $C G+1.64 \sigma_{T} 50 \%$ of the time, but he would detect an EL of $C G+2.93 \sigma_{T} 90 \%$ of the time, an EL of $C G+3.97$ oT $99 \%$ 
of the time and an EL of CG $+4.22 \sigma_{T} 99.5 \%$ of the time. This means that in $5 \%$ of the cases where the true EL is just at the CG the operator's statistics will cause him to take the action required when EL is greater than CG, but that in $50 \%$ of the cases where EL is greater than CG by $1.64 \sigma_{T}$ the statistics will indicate an under-control situation.

The use of " $2 \sigma$ " confidence 1 imits is prevalent in environmental monitoring. The best one can do using "2 $\sigma$ " limits, in terms of $\alpha$ and $\beta$ levels, can be determined from Table $A-2$ by locating the $k_{A}$ closest to 2.00 in the body of the table and reading the corresponding $\alpha$ and $\beta$ values. This exercise produces the following approximations:

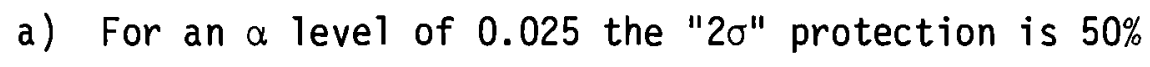

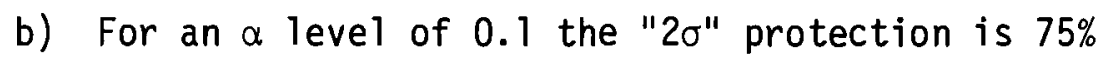

c) For an a level of 0.25 the " $2 \sigma$ " protection is $90 \%$

TABLE $A-2 . \quad k_{A}$ For Some Common Values of $\alpha$ and $\beta$

\begin{tabular}{|c|c|c|c|c|c|c|c|c|c|c|}
\hline $\begin{array}{c}100 \\
(1-\beta) \\
\alpha / \beta \\
\end{array}$ & $\begin{array}{r}50.0 \\
.5 \\
\end{array}$ & $\begin{array}{r}75.0 \\
.25 \\
\end{array}$ & $\begin{array}{r}80.0 \\
.2 \\
\end{array}$ & $\begin{array}{r}90.0 \\
.1 \\
\end{array}$ & $\begin{array}{r}95.0 \\
.05 \\
\end{array}$ & $\begin{array}{l}97.0 \\
.025 \\
\end{array}$ & $\begin{array}{r}99.0 \\
.01 \\
\end{array}$ & $\begin{array}{r}99.5 \\
.005 \\
\end{array}$ & $\begin{array}{r}99.9 \\
.001 \\
\end{array}$ & $z_{1-\alpha}$ \\
\hline .25 & .67 & 1.35 & 1.52 & 1.96 & 2.32 & 2.63 & 3.00 & 3.25 & 3.76 & .674 \\
\hline .2 & .84 & 1.52 & 1.68 & 2.12 & 2.49 & 2.80 & 3.17 & 3.42 & 3.93 & .842 \\
\hline .1 & 1.28 & 1.96 & 2.12 & 2.56 & 2.93 & 3.24 & 3.61 & 3.86 & 4.37 & 1.282 \\
\hline .05 & 1.64 & 2.32 & 2.49 & 2.93 & 3.29 & 3.61 & 3.97 & 4.22 & 4.74 & 1.645 \\
\hline .025 & $\underline{1.96}$ & 2.63 & 2.80 & 3.24 & 3.61 & 3.92 & 4.29 & 4.54 & 5.05 & 1.960 \\
\hline .01 & 2.33 & 3.00 & 3.17 & 3.61 & 3.97 & 4.29 & 4.65 & 4.90 & 5.42 & 2.326 \\
\hline .005 & 2.58 & 3.25 & 3.42 & 3.86 & 4.22 & 4.54 & 4.90 & 5.15 & 5.67 & 2.576 \\
\hline .001 & 3.09 & 3.76 & 3.93 & 4.37 & 4.74 & 5.05 & 5.42 & 5.67 & 6.18 & 3.090 \\
\hline$Z_{B}$ & 0 & .674 & .842 & 1.282 & 1.645 & 1.960 & 2.326 & 2.576 & 3.090 & \\
\hline
\end{tabular}


It could prove extremely costly to the operator to allow an a as large as 0.25 , and the $\beta-1$ evel at 0.5 associated with the $\alpha-1$ evel of 0.025 provides no better protection to the population than if the operator tossed a coin and decided that EL > CG whenever heads appeared in the situation where the true EL (unknown to the operator) is in the interval (CG, CG $\left.+2 \sigma_{T}\right)$.

The point of the above discussion was to emphasize the importance of considering the statistical risk to the population as well as the potential cost to the operator in the design of surveillance systems. The most important consideration is the amount of radioactivity represented by $k_{A} \sigma_{T}$. Given $\alpha$ and $B$, the minimum $k_{A}$ is determined by the "normal theory" case, as in Table A-2. The standard deviation of the surveillance system, $\sigma_{T}$, thus becomes the determining factor in the latitude/protection considerations. If $\sigma_{\mathrm{T}}$ is very sma 11, $2 \sigma_{\mathrm{T}}$ may represent less than $1 \%$ of the $\mathrm{CG}$. However, one known instance allows $2 \sigma_{\varepsilon}$, where $\sigma_{\varepsilon}$ is just the measurement error component of $\sigma_{T}$, to be as large as $35 \%$ of CG.

The above considerations lead to the following solution to the "Problem" specified above.

\section{Given:}

$$
\begin{aligned}
C G= & \text { a specified concentration guide value which requires } \\
& \text { some action on the part of the surveillance authority } \\
& \text { whenever a sample result, } \hat{E L} \text {, exceeds } i t, \\
\alpha= & \text { the allowed probability of stating } E L>C E \text { when in fact } E L \leq C G . \\
B= & \text { the allowed probability of stating } E L \leq C G \text { when in fact } E l>C G . \\
\sigma_{T}= & \text { the total variability due to sampling, measurement and } \\
& \text { bias correction random errors based on historical best } \\
& \text { estimates of } \sigma_{\eta}^{2}, \sigma_{\varepsilon}^{2}, \sigma_{B}^{2}, \sigma_{\delta}^{2} .
\end{aligned}
$$

The sürveillance system will be judged adequate for a particular nuclide-media combination if:

$$
100\left(R(\alpha, \beta) \sigma_{T} / C G\right)<P \%
$$


where

$$
k(\alpha, \beta)=z_{(1-\alpha)}-z_{\beta}
$$

and

$P$ is a value which both the operator and the licensing authority would be willing to have publicized as the relative protection afforded by the surveillance system.

This solution has not considered the timeless part of the criterion. A surveillance system will be judged timely if

$$
T=(R C / A F)>1.0
$$

where

$R C$ is the rate of change of the population sampled

and

AF is the frequency of sample analysis.

The interpretation of AF is straightforward. The analytical frequency may vary from continuous monitoring through real time samplers and analyzers, through, say, monthly analysis of composited weekly samples, to analysis of a single sample taken once a year. $R C$ is more difficult to interpret. If the population sampled is the air mass in the monitored area, an appropriate interpretation may be the time it takes for the total air mass to change. For example, suppose it takes an average of 8 hours for the air mass to change. Continuous monitoring with hourly read out (analysis) of counts would provide a timeliness ratio of $8 / 1$ but weekly analysis of filters would provide a ratio of only $1 / 21$. Most current surveillance practice would fall far short of the timliness criterion proposed above and the "state of the art" prohibits its attainment in most cases at anywhere near reasonable cost. Consequently, it must devolve on the licensing agency to determine what timeliness ratio, less than or equal to unity, constitutes adequate timeliness for given nuclide-media combinations. 
BNWL- 1723

UC-41

DISTRIBUTION

No. of

Copies

Off-Site

1 AEC Chicago Patent Group G.H. Lee

5 AEC Division of Operational Safety M. Biles

261 AEC Technical Information Center

42 AEC Office of the Director of Regulations J.E. Ayers

R.B. Chitwood

R.E. Cunningham

J.J. Davis

C.C. Gamertsfelder

G.R. Grove

G. Hamada

E. Held

M.D. Houston

$H$. Lowenberg

D.A. Nussbaumer

W.H. Ray

L. Rogers

L.C. Rouse

S.H. Smiley

K.G. Steyer

Regulatory Records Center (25)

2 AEC Library - Germantown, Md.

2 AEC Library - Bethesda, Md.
No. of

Copies

On-Site Hanford

1 $\frac{\text { AEC/RL Patent Attorney }}{\text { R. M. Poteat }}$

4 AEC Richland Operations Office

0.J. Elgert

P.G. Holsted (2)

B.J. Melton

97 Battelle-Northwest

E.L. A1pen

T.M. Beet7e

P.E. Bramson

L.A. Carter

N.E. Carter

J.P. Corley

D.H. Denham

C.E. Elderkin

R.F. Foster

J.J. Fuquay

J.M. Hales

J.W. Johnston

J. Mishima

W.L. Nees

H.M. Parker

W.D. Richmond

L.C. Schwendiman

J.M. Selby (20)

J.K. Soldat

C.M. Unruh

J.B. Vetrano

D.A. Waite

D.C. Watson

L.D. Wi 11 iams

R.K. Woodruff

Technical Publications (1)

Technical Information (3)

1 Atlantic Richfield Hanford Co.

G.E. Backman

$1 \quad$ United Nuclear, Inc.

C.D. Corbit

1 Westinghouse Hanford Company R.0. Budd 